\title{
NPAT links cyclin E-Cdk2 to the regulation of replication-dependent histone gene transcription
}

\author{
Jiyong Zhao, ${ }^{1,4,5}$ Brian K. Kennedy, ${ }^{1}$ Brandon D. Lawrence, ${ }^{2}$ David A. Barbie, ${ }^{1}$ A. Gregory Matera, ${ }^{3}$ \\ Jonathan A. Fletcher, ${ }^{2}$ and Ed Harlow ${ }^{1}$ \\ ${ }^{1}$ Massachusetts General Hospital Cancer Center, Charlestown, Massachusetts 02129, USA; ${ }^{2}$ Brigham and Women's \\ Hospital, Department of Pathology, Boston, Massachusetts 02115, USA; ${ }^{3}$ Case Western Reserve University, Department \\ of Genetics, Cleveland, Ohio 44106, USA
}

In eukaryotic cells, histone gene expression is one of the major events that mark entry into S phase. While this process is tightly linked to cell cycle position, how it is regulated by the cell cycle machinery is not known. Here we show that NPAT, a substrate of the cyclin E-Cdk2 complex, is associated with human replication-dependent histone gene clusters on both chromosomes 1 and 6 in S phase. We demonstrate that NPAT activates histone gene transcription and that this activation is dependent on the promoter elements (SSCSs) previously proposed to mediate cell cycle-dependent transcription. Cyclin $\mathrm{E}$ is also associated with the histone gene loci, and cyclin E-Cdk2 stimulates the NPAT-mediated activation of histone gene transcription. Thus, our results both show that NPAT is involved in a key $S$ phase event and provide a link between the cell cycle machinery and activation of histone gene transcription.

[Key Words: NPAT; cyclin E-Cdk2; histone gene transcription; nuclear foci]

Received June 15, 2000; revised version accepted July 28, 2000.

Histones are essential components of eukaryotic chromosomes and play crucial roles in the maintenance of chromosomal integrity (Kornberg and Lorch 1999). It was first reported 3 decades ago that synthesis of histone proteins occurs primarily during $S$ phase of the cell cycle (Robbins and Borun 1967). Subsequently, a large body of research has established that the $S$ phase-specific increase in histone protein levels results directly from the accumulation of histone mRNA in S phase, which in turn is controlled at the level of transcription, premRNA processing, and mRNA stability (Schumperli 1986; Heintz 1991; Osley 1991; Marzluff 1992; Stein et al. 1992; Dominski and Marzuluff 1999).

There are multiple gene copies for each histone subtype $(\mathrm{H} 1, \mathrm{H} 2 \mathrm{~A}, \mathrm{H} 2 \mathrm{~B}, \mathrm{H} 3$, and $\mathrm{H} 4)$ to accommodate the large demand for histone synthesis during DNA replication. Histone genes are classified as either replication dependent or replication independent according to their pattern of expression within the cell cycle (Heintz 1991; Osley 1991; Stein et al. 1992). Replication-independent histone genes are constitutively expressed at low levels throughout the cell cycle. The majority of vertebrate his-

\footnotetext{
${ }^{4}$ Present address: Center for Cancer Biology, University of Rochester Medical Center, Rochester, NY 14642, USA

${ }^{5}$ Corresponding author.

E-MAIL jiyong_zhao@urmc.rochester.edu; FAX (716) 273-1450.

Article and publication are at www.genesdev.org/cgi/doi/10.1101/ $\operatorname{gad} .827700$.
}

tone genes are replication dependent and are primarily expressed during $S$ phase. These replication-dependent histone genes are clustered in a small number of chromosome loci. Human replication-dependent histone genes are clustered on chromosomes 1 and 6 . Six histone genes have been identified so far in the histone gene cluster at 1q21, while $\sim 50$ histone genes have been found in the cluster at 6p21 (Albig and Doenecke 1997).

Transcriptional regulation plays an important role in replication-dependent histone gene expression at the $\mathrm{G}_{1} / \mathrm{S}$ boundary. As cells enter $\mathrm{S}$ phase, histone mRNA transcription increases three- to 10-fold compared to the basal level in $G_{1}$ phase (Heintz 1991). Studies on $H 1$, $\mathrm{H} 2 \mathrm{~B}$, and $\mathrm{H} 4$ promoters suggest that the cell cycle-dependent transcription of histone genes is effected through distinct subtype-specific consensus elements (SSCSs), which are occupied by protein factors in vivo (Heintz 1991; Osley 1991). OTF1/Oct-1 interacts with the core octamer sequence in the H2B SSCS and stimulates H2B transcription in vitro (Fletcher et al. 1987; Segil et al. 1991). There are two SSCSs in the H1 promoter (La Bella et al. 1989; Heintz 1991). H1TF2, which is composed of two subunits, interacts with the proximal SSCS (Martinelli and Heintz 1994). The human H4 SSCS is located in a promoter region that interacts with multiple protein factors (Hanly et al. 1985; Heintz 1991; van Wijnen et al. 1992). 4FT2/HiNF-P has been identified and purified as the factor that binds H4 SSCS (Dailey et 
al. 1988). Another sequence motif in the site II region of human $\mathrm{H} 4$ gene FO108 promoter that overlaps with the H4 SSCS has also been suggested to mediate cell cycledependent transcription of this $\mathrm{H} 4$ promoter (RamseyEwing et al. 1994; Vaughan et al. 1995; van Wijnen et al. 1996). Binding sites for the transcription factor E2F have been found in H2A promoters, and it has been reported that E2F activates transcription from H2A.1 promoter (Yagi et al. 1995; Oswald et al. 1996). A region that contains AP-1 and AP-2 binding sites in a hamster histone $\mathrm{H} 3$ gene has been shown to be required for high levels of transcription and $\mathrm{S}$ phase activation, and binding of AP-2 to this site has been suggested to regulate this $\mathrm{H} 3$ promoter (Artishevsky et al. 1987; Wu and Lee 1998).

The observations discussed above suggest that transcriptional regulation of each subtype of the histone genes may involve a different set of factors. Given that transcription of all five vertebrate subtype histone genes is coordinately activated on entry into $S$ phase, there must be an upstream regulatory mechanism that transduces a common signal for the activation of histone gene transcription when cells reach the $G_{1} / S$ boundary (Heintz 1991; Osley 1991). This mechanism has so far remained elusive. As histone synthesis is closely linked to the $S$ phase of the cell cycle, it is reasonable to assume that this process must be controlled by the cell cycle machinery at some level. Yet this connection has not been characterized.

The cyclin E-Cdk2 kinase complex is a key regulator of $S$ phase entry in animal cells. The activity of cyclin E-Cdk2 peaks at the $\mathrm{G}_{1} / \mathrm{S}$ boundary (Dulic et al. 1992; Koff et al. 1992). Forced expression of cyclin E promotes $S$ phase entry, while blocking the kinase activity of the cyclin E-Cdk2 complex inhibits the $\mathrm{G}_{1}$-to-S phase transition /Ohtsubo and Roberts 1993; Tsai et al. 1993; van den Heuvel and Harlow 1993; Resnitzky et al. 1994; Ohtsubo et al. 1995). Two major S phase events, DNA replication and centrosome duplication, have been shown to require the activity of cyclin E-Cdk2 (Fang and Newport 1991; Jackson et al. 1995; Hinchcliffe et al. 1999; Lacey et al. 1999). However, the kinase targets in these events have yet to be identified. Proteins that are involved in several diverse cellular activities have been identified as the substrates of cyclin E-Cdk2 (Hinds et al. 1992; Zhu et al. 1995; Herrera et al. 1996; Perkins et al. 1997; Sheaff et al. 1997; Jiang et al. 1998; Seghezzi et al. 1998; Harbour et al. 1999; Ruffner et al. 1999; Shanahan et al. 1999), though in most cases it remains unclear how phosphorylation of these substrates directly contributes to $S$ phase entry.

We previously reported the identification of NPAT as a cyclin E-Cdk2 substrate (Zhao et al. 1998). The protein interacts with cyclin E-Cdk2 both in vitro and in vivo, and it can be phosphorylated by the kinase complexes. Overexpression of NPAT promotes S phase entry, and coexpression of cyclin E-Cdk2 enhances the effects of NPAT on cell cycle progression. From these findings we suggested that NPAT is likely to be a physiologically relevant substrate of cyclin E-Cdk2 that may play an important role in S phase entry (Zhao et al. 1998). How- ever, the biological function of NPAT has not been elucidated.

In this study, we have investigated the function of NPAT initially by examining its localization in human cells. We demonstrate that NPAT is concentrated at a few discrete foci in the nucleus and the number of NPAT foci changes in a cell cycle-dependent manner in primary human cells. Interestingly, we found that these NPAT foci colocalize with the histone gene clusters. We show that NPAT activates replication-dependent histone gene transcription and that the NPAT-mediated transcriptional activation is further enhanced by the cyclin E-Cdk2 complex. These results illustrate that NPAT is involved in an S phase event and links cyclin E-Cdk2 to the activation of histone gene transcription.

\section{Results}

NPAT is concentrated at a few foci in the nucleus

We previously have characterized the NPAT gene and shown that its protein product physically interacts with cyclin E/CDK2 and can be phosphorylated by this kinase. As a next step in characterizing the function of NPAT, we examined its subcellular localization in several human cell lines by indirect immunofluorescence (IF), using specific anti-NPAT antibodies. As shown in Figure 1A, NPAT is concentrated in a few prominent foci in the nuclei of human cells. Although the possibility that the protein may also be dispersed throughout the nucleus at much lower concentrations cannot be ruled out, the focal staining pattern is dramatic in all cell lines tested. Through a careful study of many normal cells and transformed cell lines, we noted that there are more NPAT foci in transformed cell lines than in primary cells, and this difference will be discussed later. In our initial experiments, we concentrated on the staining pattern of NPAT in primary cells.

To ensure that the distinct nuclear foci were due to authentic NPAT protein and not to an unexpected antibody cross-reaction, we examined the localization of NPAT with multiple monoclonal and polyclonal NPAT antibodies directed against different regions of the NPAT protein. All anti-NPAT antibodies exhibit the same prominent staining pattern, and the patterns seen with each antibody show complete overlap (Fig. 1B; data not shown), demonstrating unambiguously that the foci labeled by our antibodies are indeed NPAT protein.

The number of NPAT foci changes in a cell cycle-dependent manner

During the examination of the NPAT protein in primary cells, such as in human fibroblasts WI38 and MRC5 or in human epidermal keratinocytes (data not shown), we noted that the number of NPAT foci (spots) was either two or four in interphase cells (Fig. 1A-C). To test whether there is any relationship between the number of detectable NPAT spots and the S phase of the cell cycle, 
A
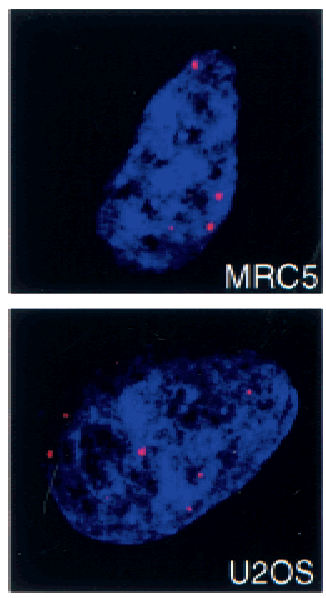

B
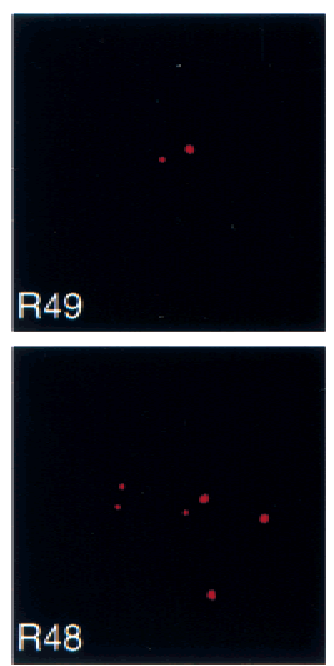
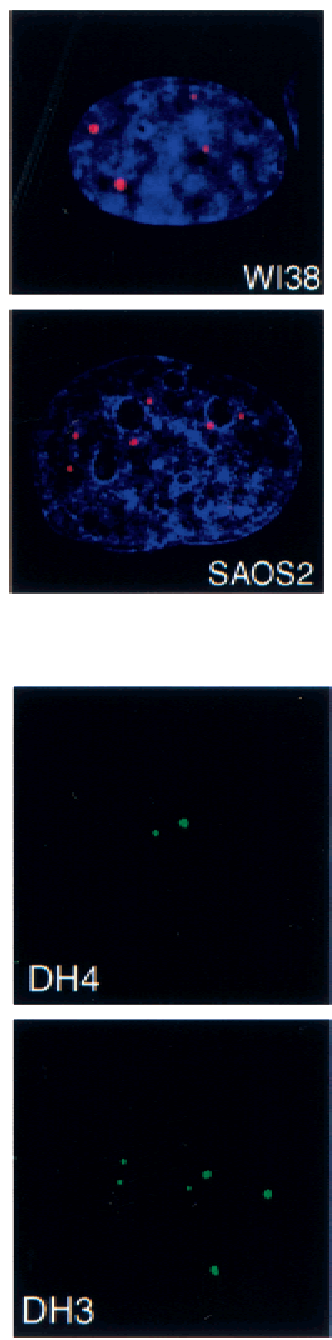
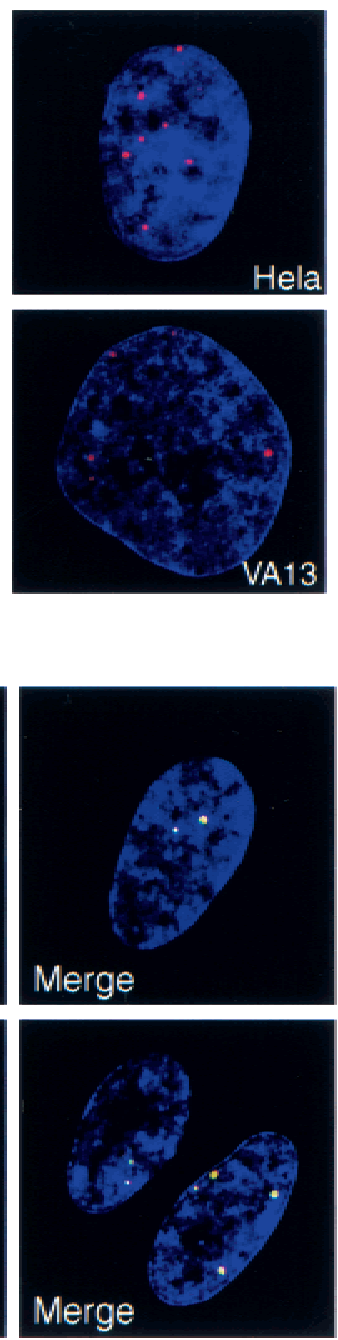

C

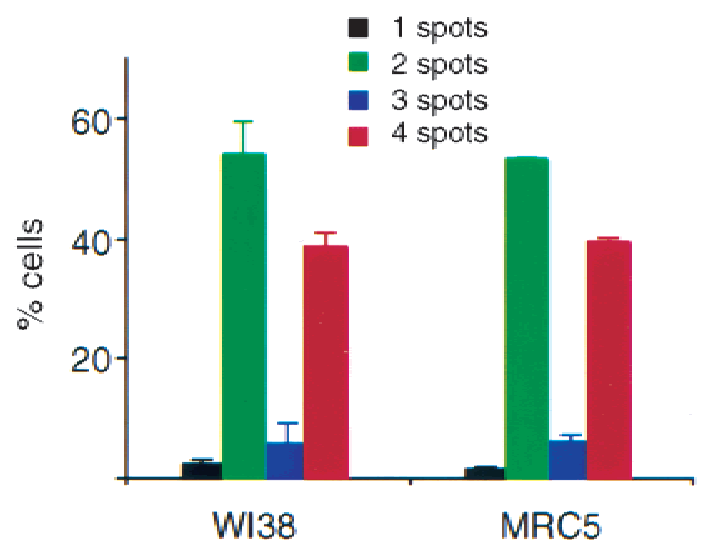

Figure 1. NPAT concentrates at a few foci in the nuclei of human cells. (A) Localization of NPAT in the indicated cell lines was examined by indirect immunofluorescence (IF) using an affinity-purified rabbit anti-NPAT antibody (R48). The antirabbit IgG secondary antibody was conjugated with Texas Red (Red). Nuclear DNA (nucleus) was stained with DAPI (blue). (B) Multiple NPAT antibodies recognize the same NPAT foci. WI38 cells were double stained with a mouse monoclonal NPAT antibody (DH3 or DH4) and an affinity-purified rabbit polyclonal NPAT antibody (R48 or R49). The staining from the mouse antibodies (green) and that from the rabbit antibodies (red) are completely overlapping (yellow). (C) Most WI38 and MRC5 cells have two or four NPAT foci (spots). WI38 and MRC5 cells were stained with R48, and the number of NPAT spots in each cell was counted. The mean results from three independent experiments and the standard deviations are shown. More than 200 cells were analyzed in each experiment. we treated WI38 cells with a short pulse of bromodeoxyuridine (BrdU) to label the cells in S phase and examined the number of NPAT spots in both BrdU-positive (S phase) and BrdU-negative (non-S phase) cells. While there are four NPAT spots in S phase cells, only two NPAT spots are observed in non-S phase cells (Fig. $2 \mathrm{~A}, \mathrm{~B})$. This suggested that that there is a link between the number of NPAT spots and the phase of the cell cycle. This prompted us to investigate the NPAT staining pattern during the cell cycle in more detail. The distribution of NPAT in WI38 cells at different time points was examined after the cells were released from serum starvation (Fig. 3). Serum-starved $\left(G_{0}\right)$ cells have either two weakly stained NPAT spots or no detectable foci (data not shown), consistent with our observations from Western blotting experiments that the level of NPAT protein in serum-starved cells is much lower than in growing cells (data not shown). When cells enter $\mathrm{G}_{1}$ phase, the number of NPAT spots remains two, but the staining is much brighter than in $\mathrm{G}_{0}$. The number of NPAT spots becomes four when cells reach $S$ phase, as indicated by the coincidence of BrdU incorporation and the appearance of four spots. In $\mathrm{G}_{2}$, the number of NPAT spots returns to two (Fig. 3; data not shown). There remain two prominent NPAT spots until early prometaphase. NPAT becomes dispersed at late prometaphase/ metaphase and remains dispersed throughout the rest of the mitosis (Fig. 3; data not shown). We also observed identical cell cycle-dependent changes in the NPAT staining pattern in primary human fibroblast MRC5 cells (data not shown). The appearance and disappearance of NPAT spots during the cell cycle most likely reflects cell cycle-dependent assembly and disassembly of NPAT protein at these foci. As S phase cells have the highest number of NPAT spots and our previous experiments showed that NPAT may play an important role for S phase entry (Zhao et al. 1998), we speculated that the prominent spots detected by anti-NPAT antibodies may mark locations where NPAT exerts its function(s).

NPAT protein is associated with histone gene clusters in $S$ phase

To investigate the significance of NPAT localization, we 
Zhao et al.
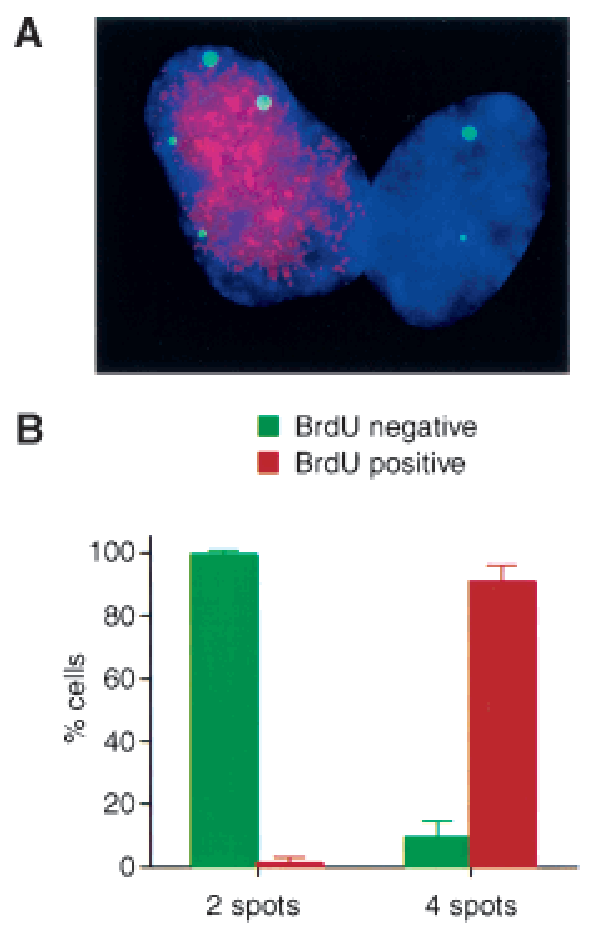

Figure 2. There are four NPAT spots in S phase cells and two NPAT spots in non-S phase cells. (A) WI38 cells were incubated with $50 \mu \mathrm{M}$ BrdU for $3.5 \mathrm{~h}$, fixed, and stained with a mouse anti-BrdU antibody (red) and the rabbit anti-NPAT antibody R48 (green). DNA was stained with DAPI (blue). (B) WI38 cells were incubated with BrdU for $20 \mathrm{~min}$ and then fixed and stained as described in A. 100-150 cells were analyzed for the number of NPAT spots and BrdU staining status. The mean results from three independent experiments are depicted. The bars represent the standard deviations.

set out to identify the location of the NPAT spots within the interphase nucleus. We examined the colocalization of NPAT with a number of proteins that have been reported to form a small number of nuclear foci. We found no overlap of NPAT with PML (PML bodies; Dyck et al. 1994; Fig. 4), UBF (a nucleolar marker; Jantzen et al. 1990), or SC-35 (a splicing factor; Fu and Maniatis 1990; data not shown). However, as shown in Figure 4, the staining of NPAT exhibits partial overlap with that of p80 coilin, a marker protein for coiled bodies (Raska et al. 1990; Andrade et al. 1991). The experiment shown in Figure 4 was performed with U2OS cells, in which the typical number of NPAT foci is between five and eight. We have also observed partial colocalization of NPAT with coilin in WI38 cells (data not shown), although coilin is more dispersed in these cells (Raska et al. 1990; Huang and Spector 1992).

Coiled bodies are subnuclear structures conserved in the nuclei of higher eukaryotes. The function of coiled bodies remains to be elucidated, although it has been suggested that they are involved in snRNP biogenesis and RNA processing (Lamond and Earnshaw 1998; Matera 1999). Interestingly, coiled bodies are often associated with several specific chromosomal loci, including the histone gene clusters (Frey and Matera 1995). This led us to wonder whether NPAT is also associated with any of these loci.

As the histone genes in these clusters are expressed significantly only in S phase, and as NPAT is known to promote $\mathrm{S}$ phase entry, we examined whether NPAT is associated with the histone gene clusters on chromosome 1q21 and 6p21 by immunofluorescence (IF) combined with fluorescence in situ hybridization (FISH). In these experiments, NPAT protein was probed with specific anti-NPAT antibodies and the histone gene loci were identified with specific DNA probes. As shown in Figure 5A, the NPAT spots are associated with histone gene loci on chromosomes 1 and 6 . While the association of NPAT with the histone gene cluster on chromosome 6 is detected in all cells, the association of NPAT spots with the chromosome 1 cluster is observed only in cells that have four detectable NPAT spots. This observation suggests that the association of NPAT spots with the chromosome 1 histone gene cluster is cell cycle dependent. Three-color staining experiments (Fig. 5B), in which DNA probes specific for both histone gene clusters were used simultaneously with an anti-NPAT antibody, further confirmed the above observations and demonstrated that all four NPAT spots are associated with histone gene clusters in S phase. Thus, NPAT localizes to all histone gene clusters in $\mathrm{S}$ phase when these genes are actively expressed.

In the cells that have four NPAT foci, there are spots of two different sizes (Figs. 2,3,5). The two smaller NPAT spots are always associated with the smaller histone gene cluster on chromosome 1 , and the two bigger NPAT spots are always associated with the larger histone gene cluster on chromosome 6 . This observation is consistent with the idea that NPAT may physically interact with the histone gene loci in S phase of the cell cycle (see below). Transformed cells, which are aneuploid, contain extra copies of chromosomes 1 and 6. NPAT is associated with each of the histone gene clusters on these chromosomes and, thus, more than four NPAT spots are observed in these cells (Figs. 1A, 4; data not shown). Taken together, these results suggest that NPAT may play a role in the expression of histone genes during $\mathrm{S}$ phase of the cell cycle.

\section{NPAT activates histone gene transcription}

As discussed above, transcriptional regulation plays a critical role in histone gene expression at the $G_{1} / S$ phase boundary, and this cell cycle-dependent regulation is mediated by proximal promoter elements (Heintz 1991; Osley 1991; Stein et al. 1992). To determine whether expression of NPAT has any effect on histone gene transcription, we studied several histone promoters for regulation by NPAT. The most dramatic effect was seen with the histone $\mathrm{H} 4$ promoters. Two well-studied histone $\mathrm{H} 4$ promoters were fused independently to a luciferase gene reporter, and the effects of NPAT on transcription from these $\mathrm{H} 4$ promoters were assayed in transient transfec- 

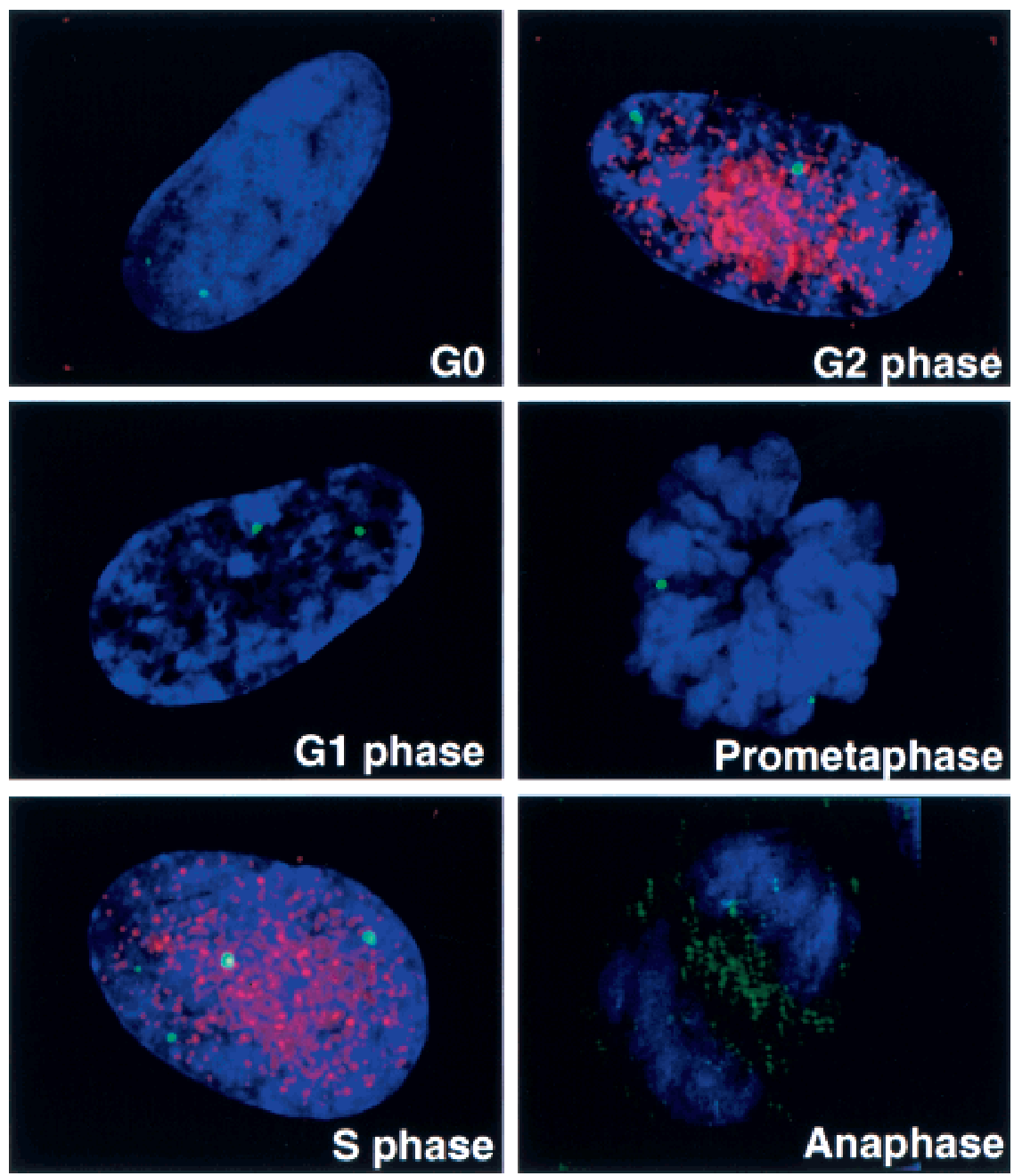

Figure 3. The localization of NPAT changes during the cell cycle. WI38 cells were arrested at $\mathrm{G}_{0}$ by serum starvation as previously described (Tsai et al. 1993). At the time when the cells were released from the arrest, BrdU (final concentration $50 \mu M$ ) was added into the culture medium. The cells were fixed, permeablized, and stained as described for Figure 2 at $6 \mathrm{~h}\left(\mathrm{G}_{1}\right.$ phase), $19 \mathrm{~h}(\mathrm{~S}$ phase), $24 \mathrm{~h}$ $\left(\mathrm{G}_{2}\right)$, and $28 \mathrm{~h}$ (M phase) after release. The $\mathrm{G}_{0}$ (serum-starved) cells were treated with BrdU for $24 \mathrm{~h}$ before being fixed. The BrdU staining for the cells in $\mathrm{M}$ phase is not shown.

tion experiments. One reporter construct, pGLH4-1, contains the promoter sequence of the F0108 H4 gene, which is located on chromosome 1 (Allen et al. 1991; Ramsey-Ewing et al. 1994; van Wijnen et al. 1992, 1996; Albig and Doenecke 1997). The other reporter construct, pGLH4, has the promoter sequence of the pHu4A (H4/e) gene, which is located on chromosome 6 (Hanly et al. 1985; Dailey et al. 1987, 1988; Albig and Doenecke 1997). As shown in Figure 6A, expression of NPAT dramatically increases the transcription from these $\mathrm{H} 4$ promoters. In contrast, NPAT has no significant effect on transcription from the SV40 promoter (control) or from the b-myb and dhfr promoters, which are also activated during the $\mathrm{G}_{1}$-to-S phase transition (Lam and Watson 1993; Wells et al. 1997). These results indicate that NPAT expression specifically stimulates histone $\mathrm{H} 4$ gene transcription.

To determine which sequence elements in the histone $\mathrm{H} 4 / \mathrm{e}$ promoter mediate the response to NPAT activa- tion, we made several deletion constructs and assayed the effects of NPAT on the transcription from these mutant promoters. Deletions of the sequences between 120 and 65 base pairs upstream from transcription initiation site $(-120$ to -65$)$ cause gradual decreases in the basal level of transcription (without transfection of NPAT; Fig. 6B) as reported in previous in vitro studies (Hanly et al. 1985). However, these deletions are still responsive to transcriptional activation by NPAT (Fig. 6C). In fact, deletion of the region between -120 and -80 led to an increase in the fold of activation seen by cotransfection of NPAT, suggesting that there might be a negative regulatory sequence in this region. Additional work will be needed to identify this negative-regulatory sequence. Further deletion of nucleotides -65 to -40 completely abolishes the transcriptional activation by NPAT (Fig. 6C). These results suggest that the sequence between nucleotides -65 and -40 is required for NPAT-mediated transcriptional activation. 


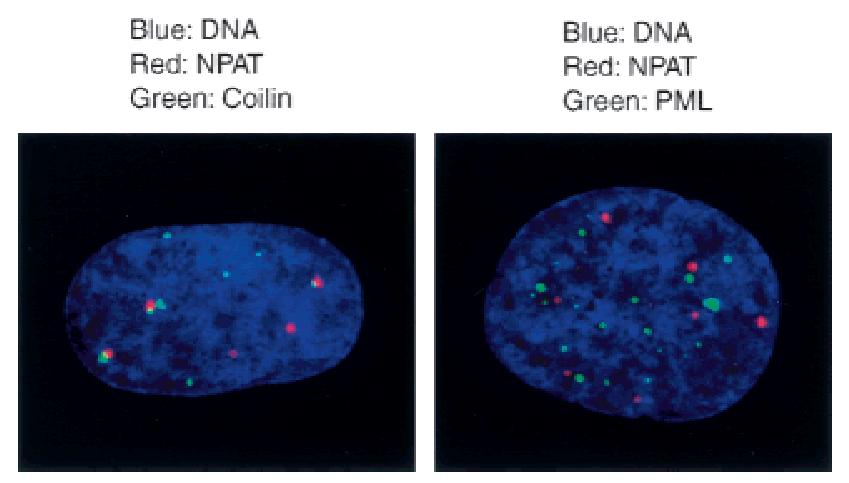

Figure 4. NPAT overlaps with coiled bodies. U2OS cells were double stained with the rabbit anti-NPAT antibody (R48; red) and a mouse monoclonal antibody 5P10 (green; left panel) or with the mouse anti-NPAT monoclonal antibody (DH4; red) and a rabbit anti-PML antibody (green; right panel). The extent of overlap between NPAT and coilin varies from cell to cell and from cell line to cell line (data not shown).

This finding is quite interesting as this region contains the histone H4 SSCS (Hanly et al. 1985; Heintz 1991). The human histone H4 SSCS is highly conserved among human histone $\mathrm{H} 4$ promoters and is thought to be the crucial control element mediating S phase-specific transcription of the histone $\mathrm{H} 4$ gene family (Dailey et al. 1988; Heintz 1991). To test directly whether the H4 SSCS is required for NPAT activation, we made two more mutant promoter constructs: pGLH4 (D1) and pGLH4 (M1). While pGLH4 (D1) has an internal deletion of nucleotides from -65 to -40 , pGLH4 (M1) is identical to the wild type except for 3-bp substitutions within the H4 SSCS that abolish the binding for H4TF-2, a factor proposed to be involved in cell cycle-dependent transcription of H4 gene transcription (Dailey et al. 1987, 1988). As shown in Figure 6B, these mutations decrease the basal transcription, suggesting that the H4 SSCS is involved in the $\mathrm{H} 4$ transcription in vivo. More important, both mutations abrogate the $\mathrm{H} 4$ transcriptional activation by NPAT (Fig. 6C), demonstrating that the $\mathrm{H} 4$ SSCS is the essential promoter element that mediates the $\mathrm{H} 4$ transcriptional activation by NPAT. These results further support the notion that NPAT positively regulates histone $\mathrm{H} 4$ gene transcription during $\mathrm{S}$ phase entry.

As expression of NPAT promotes $S$ phase entry and histone gene transcription increases as cells enter $S$ phase, it is possible that the increased histone H4 transcription is merely the result of the cell cycle effect of NPAT expression (i.e., higher percentage of cells in $S$ phase). We carried out several experiments to test this possibility. First, we assayed the effect of NPAT expression on the histone $\mathrm{H} 4$ transcription in U2OS cells at a much earlier time point after transfection when no cell cycle effect of NPAT was detectable by FACS analysis (Zhao et al. 1998). Figure 7A shows that transcription from the histone $\mathrm{H} 4$ promoter is also increased by NPAT expression at $22 \mathrm{hr}$ after transfection when the NPATtransfected cells display the same cell cycle distribution as vector-transfected cells when measured by both FACS analysis and BrdU incorporation (Table 1). Next, we examined the effects of NPAT on the histone H4 expression in SAOS2 cells, where transfection of NPAT has no effect on cell cycle distribution (Table 1). Similarly, histone $\mathrm{H} 4$ transcription is greatly increased by NPAT expression in SAOS2 cells (Fig. 7A). In the third set of experiments, we treated the transfected cells with nocodazole to arrest the cells in $\mathrm{M}$ phase and then examined the effect of NPAT expression on histone $\mathrm{H} 4$ expression in cells shortly after release from $M$ phase arrest. As shown in Figure 7B (and data not shown), both vectorand NPAT-transfected U2OS cells have not reached S phase at $2.5 \mathrm{hr}$ after being released from $\mathrm{M}$ phase. $\mathrm{Nev}$ ertheless, transcription from the $\mathrm{H} 4$ promoter is greatly activated in NPAT transfected cells (Fig. 7B). Last, we used p27, a CDK inhibitor (Polyak et al. 1994; Toyoshima and Hunter 1994), to block the cell cycle in $\mathrm{G}_{1}$ phase and assayed the effect of NPAT expression on histone $\mathrm{H} 4$ transcription in these $\mathrm{G}_{1}$ cells. When U2OS cells were transfected with a p27 expression plasmid (transfected either alone or with NPAT), $>90 \%$ of transfected cells were in $G_{1}$ phase (data not shown). Figure $7 C$ shows that the transcription from the $\mathrm{H} 4$ promoter is activated by NPAT in the presence of $\mathrm{p} 27$, albeit at lower magnitude. The possible reason for the observed decrease in the presence of $\mathrm{p} 27$ will be discussed later. In summary, these results demonstrate that stimulation of histone $\mathrm{H} 4$ transcription by NPAT is not simply a result of the cell cycle effect of NPAT overexpression.

Most of the previously identified factors involved in histone gene transcription appear to be subtype specific. To test whether NPAT activates the transcription of other subtypes of histone genes in addition to histone $\mathrm{H} 4$ genes, we examined the effect of NPAT on transcription from a well-characterized histone $\mathrm{H} 2 \mathrm{~B}$ promoter (Sive et al. 1986; LaBella et al. 1988). As shown in Figure 8, expression of NPAT also stimulates the transcription from this histone H2B promoter. Significantly, the effect of NPAT on H2B transcription is diminished when the SSCS sequence is mutated (Fig. 8), demonstrating that the stimulation of $\mathrm{H} 2 \mathrm{~B}$ transcription by NPAT depends on the H2B SSCS, a sequence that is bound by Oct-1 and shown to be involved in the cell cycle-dependent transcription of histone H2B genes (Sive et al. 1986; Fletcher et al. 1987; LaBella et al. 1988). We have also observed the stimulation of histone $\mathrm{H} 3$ transcription by NPAT (Fig. 8). The effects of NPAT on the transcription of histone $\mathrm{H} 1$ and $\mathrm{H} 2 \mathrm{~A}$ remain to be tested. Nevertheless, the results shown here indicate that NPAT activates transcription of multiple subtypes of histone genes. Taken together with the fact that endogenous NPAT protein is highly concentrated at and associated with all histone gene clusters in S phase (Fig. 5), we postulate that NPAT is a cell cycle-regulated transcription factor that activates $S$ phase-dependent transcription of histone genes.

Cyclin E-Cdk2 regulates NPAT-mediated activation of histone gene transcription

NPAT was identified as a substrate of cyclin E-Cdk2, 
A
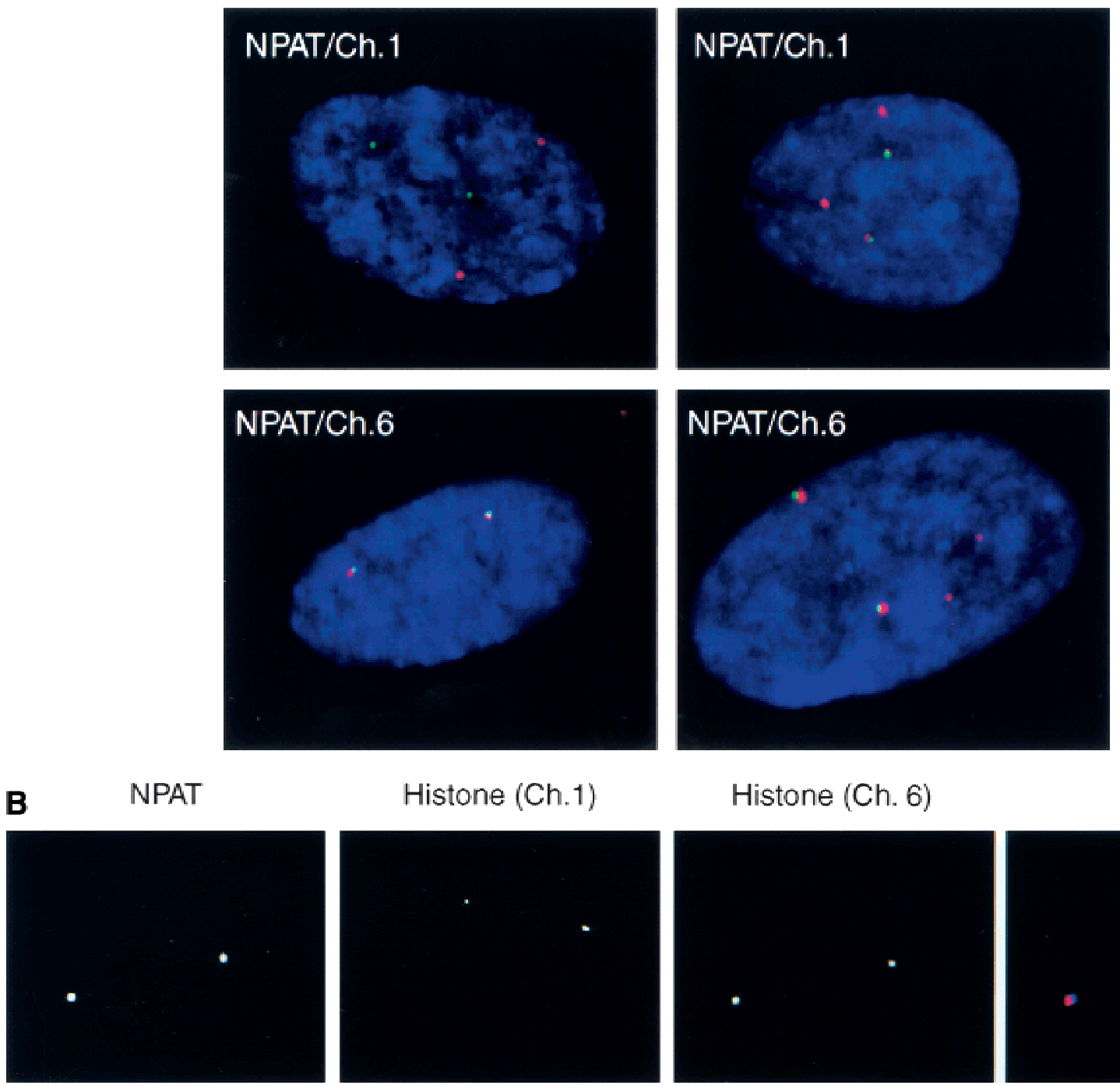

Histone (Ch.1)

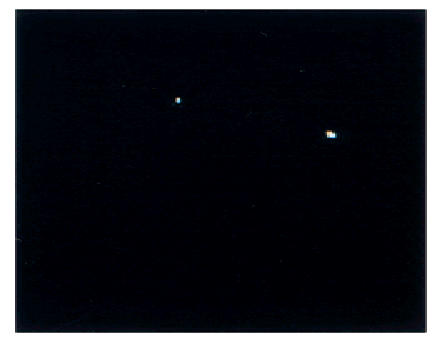

Histone (Ch. 6)
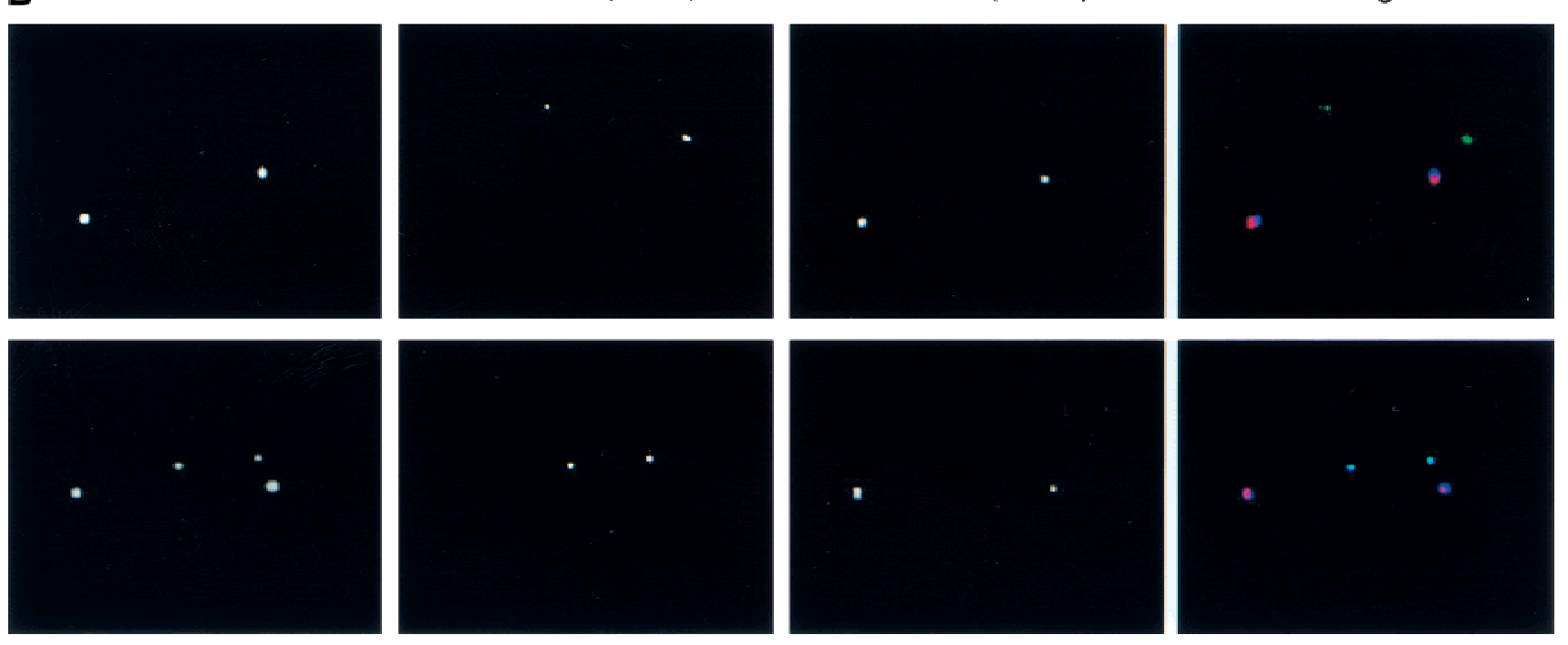

Figure 5. NPAT associates with histone gene clusters on both chromosomes 1 and 6 in $\mathrm{S}$ phase. (A) The NPAT spots are associated with histone gene clusters on chromosome 1 and 6 . WI38 cells were first stained with the rabbit anti-NPAT antibody (R48; red), fixed again, and hybridized with DIG labeled histone cluster-specific DNA probes (green). The nuclear DNA was stained with DAPI (blue). Top panels, images obtained with the probe specific for the histone cluster on chromosome 1; bottom panels, images with the probe specific for chromosome 6 cluster. For each probe, two cells, one with two NPAT spots (left panels) and one with four NPAT spots (right panels), are shown. Note that overlap of IF (red) and FISH (green) staining results in yellow dot. (B) All NPAT spots are associated with histone clusters in S phase. WI38 cells were first stained with the rabbit anti-NPAT antibody (R48; blue), fixed again, and hybridized with probes specific for chromosome 1 (green) and chromosome 6 (red) histone gene clusters. For easy viewing, the colors in the figure (except for the merged images) were shown as black and white. The results presented in this figure have been reproducibly observed in multiple independent experiments. 
Zhao et al.
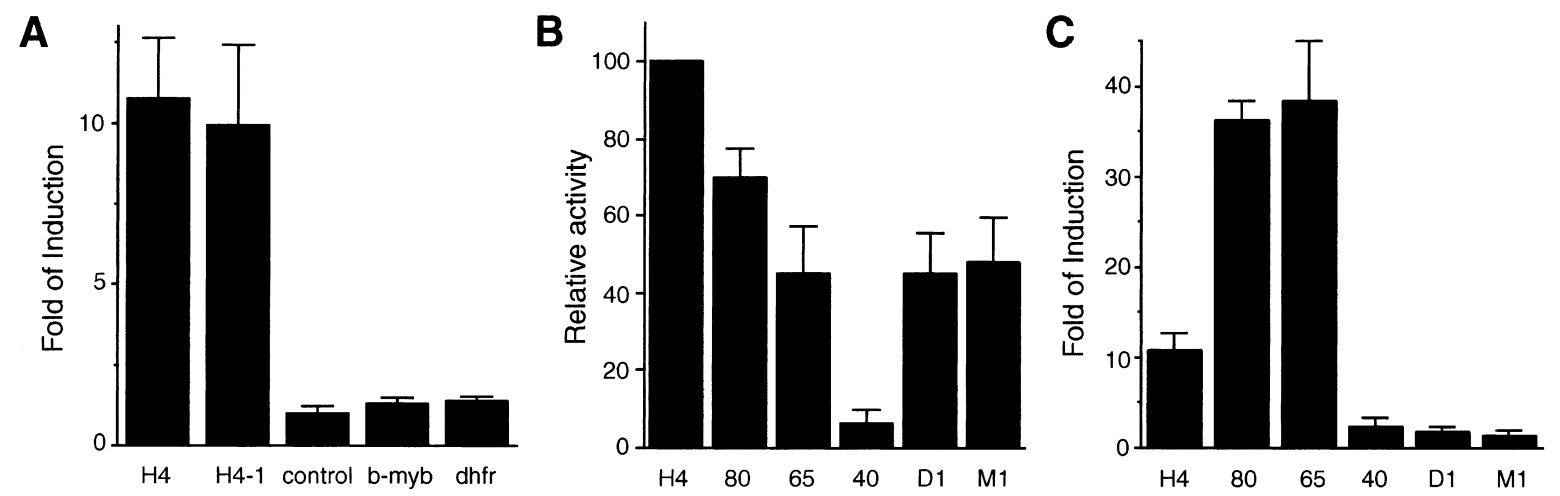

Figure 6. NPAT activates histone $\mathrm{H} 4$ transcription. $(A)$ NPAT activates transcription from $\mathrm{H} 4$ promoters. U2OS cells were transfected with $1 \mu \mathrm{g}$ pCMV (vector) or $1 \mu \mathrm{g}$ pCMV-NPAT together with 50 ng pGLH4 (labeled as H4), pGLH4-1 (labeled as H4-1), pGL3 control (labeled as Control), pGL-b-bmyb (labeled as b-myb), or pGL-dhfr (labeled as dhfr) reporter construct. Fifty ng pCMV-lacZ was also co-transfected in each transfection. Thirty-six hours after transfection, cells were lysed and the activities of $\beta$-galactosidase and luciferase were assayed as described in Materials and Methods. The activities of the $\beta$-galactosidase were used to normalize the transfection efficiency among different samples. Fold of induction was calculated by comparing the luciferase activity from NPATtransfected cells with that from the vector transfected cells. The figure shows the mean results and standard deviations from at least three independent experiments. (B) U2OS cells were transfected with $1 \mu$ g pCMV together with 50 ng pGLH4, pGLH4(80), pGLH4(65), pGLH4(40), pGLH4(D1), or pGLH4(M1) (as indicated as H4, 80, 65, 40, D1, and M1, respectively). Thirty-six hours after transfection, the cells were lysed and the $\beta$-galctosidase and luciferase activities were measured as described in $A$. The data represent the results from at least three independent experiments. $(C)$ Activation of histone $\mathrm{H} 4$ transcription by NPAT is dependent on the H4 SSCS. U2OS cells were transfected with $1 \mu \mathrm{g}$ vector or $1 \mu \mathrm{g}$ pCMV-NPAT together with $50 \mathrm{ng}$ of indicated reporter construct. Thirty-six hours after transfection, the samples were analyzed as described in $A$. H4, 80, 65,40, D1, and M1 represent the plasmids as described in $B$. The means and standard deviations from at least three independent experiments are depicted.

and coexpression of cyclin E-Cdk2 was shown to enhance the effect of NPAT on S phase entry (Zhao et al. 1998). It is therefore possible that the cyclin E-Cdk2 complex also regulates the effect of NPAT on histone transcription. To test this possibility, we transfected cyclin E/Cdk2 expression plasmids in U2OS cells with or without NPAT expression plasmid and measured the effects on transcription from a histone $\mathrm{H} 4$ promoter. While overexpression of cyclin E-Cdk2 alone has no significant effect on transcription from the $\mathrm{H} 4$ promoter (Fig. 9A), cyclin E-Cdk2 stimulated the effect of NPAT on H4 transcription when coexpressed with NPAT (Fig. 9A).
A

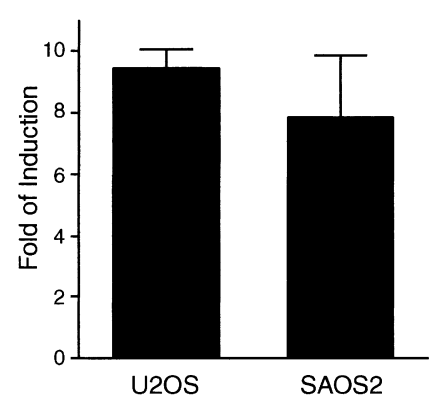

B

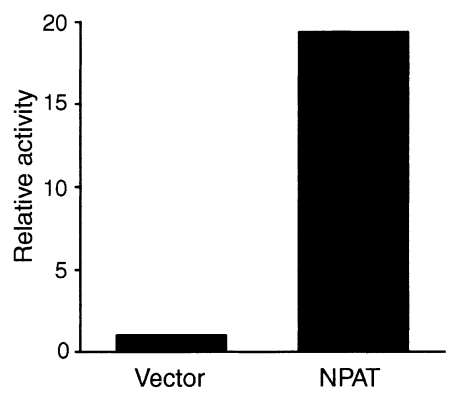

C

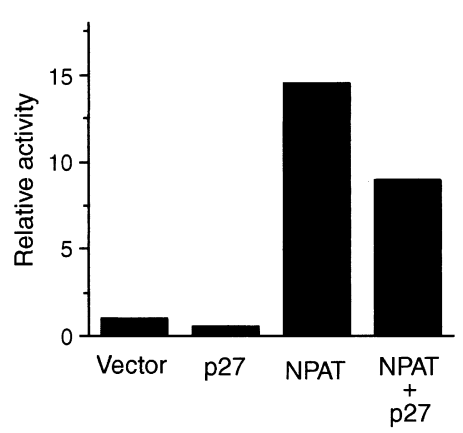

Figure 7. NPAT activates histone H4 transcription independent of its cell cycle effects. $(A)$ U2OS or SAOS2 cells were transfected as described in Fig. 6A. The transfected U2OS and SAOS2 cells were lysed at $22 \mathrm{~h}$ and $36 \mathrm{~h}$, respectively, after transfection. The samples were analyzed as described in Fig. 6A. The results from three independent experiments are shown. $(B)$ U2OS cells, grown on 10-cm plates, were transfected with $6 \mu \mathrm{g}$ pCMV (vector) or $6 \mu \mathrm{g}$ pCMV-NPAT together with $300 \mathrm{ng}$ pGLH4(65) and 300 ng pCMV-lacZ. Five hours after transfection, Nocadazole (final concentration $70 \mathrm{ng} / \mathrm{mL}$ ) was added into the culture medium to arrest the cells in $\mathrm{M}$ phase. Eighteen hours later, cells in M phase were harvested by mitotic shake-off. The cells were washed twice with culture medium and replated. Two and one-half hours after replating, the distribution of the cells in the cell cycle was analyzed by FACS and the effect of NPAT on $\mathrm{H} 4$ transcription was analyzed as described in Fig. 6A. The mean results from two independent experiments are shown. (C) U2OS cells were transfected with 50 ng pGLH4 (65) together with pCMV vector (1 $\mu \mathrm{g}$ ), p27 (100 ng), NPAT (0.5 $\mu \mathrm{g}$ ), or NPAT plus p27 as indicated. Thirty-six hours after transfection, the samples were analyzed as described in Fig. 6A. The data represent the mean from two independent experiments. 
Table 1. Cell cycle distribution of vector and NPAT transfected cells

\begin{tabular}{cccccccc}
\hline & \multicolumn{3}{c}{ U2OS } & & \multicolumn{3}{c}{ SAOS2 } \\
\cline { 2 - 4 } \cline { 6 - 8 } & $\mathrm{G}_{1}$ & $\mathrm{~S}$ & $\mathrm{G}_{2} / \mathrm{M}$ & & $\mathrm{G}_{1}$ & $\mathrm{~S}$ & $\mathrm{G}_{2} / \mathrm{M}$ \\
\hline Vector & 61.6 & 30.6 & 8.3 & & 41.2 & 25.3 & 33.5 \\
NPAT & 61.2 & 29.8 & 9.0 & & 40.3 & 26.5 & 33.2 \\
\hline
\end{tabular}

U2OS or SAOS2 cells transfected with pCMV (vector) or pCMV-NPAT as indicated. The cells were harvested at $22 \mathrm{~h}$ (U2OS) or $36 \mathrm{~h}$ (SAOS2) after transfection, and the distributions of transfected cells in the cell cycle were analyzed by FACS as previously described (Zhao et al. 1998). When measured by BrdU incorporation as described in Materials and Methods, 38\% of both vector- and NPAT-transfected U2OS cells are in S phase, while $30 \%$ of both vector- and NPAT-transfected SAOS2 cells are in $S$ phase. The data represent the mean results from two independent experiments.

Furthermore, this stimulation by cyclin E-Cdk2 was also dependent on the H4 SSCS. (Fig. 9B). These results suggest that NPAT is a limiting factor in H4 transcription and that cyclin E-Cdk2 may positively regulate histone gene transcription through the downstream target NPAT. This suggestion may also explain the observation that $\mathrm{p} 27$, whose expression blocks the activity of cyclin E-Cdk2, inhibited the effect of NPAT on the transcription from the histone $\mathrm{H} 4$ promoter $(40 \%$ inhibition under the experimental condition; Fig. 7C). As a control for the specificity of this stimulation of cyclin E-Cdk2 on NPAT, we also tested the effect of coexpression of cyclin $\mathrm{D} 1 / \mathrm{Cdk} 4$, another $\mathrm{G}_{1}$ cyclin dependent kinase that is known to drive a shortening of $\mathrm{G}_{1}$ phase. In contrast to

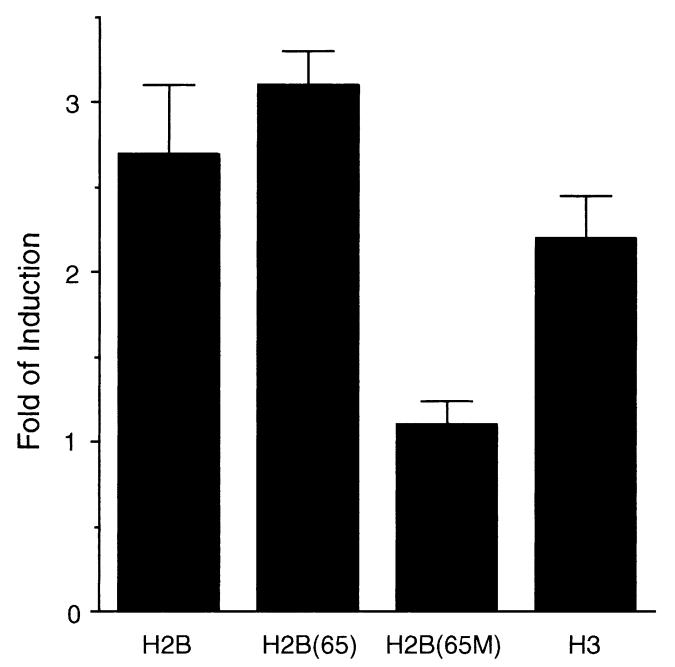

Figure 8. NPAT also activates transcription from histone $\mathrm{H} 2 \mathrm{~B}$ and $\mathrm{H} 3$ promoters. U2OS cells were transfected with $1 \mu \mathrm{g}$ pCMV (vector) or $1 \mathrm{\mu g}$ pCMV-NPAT together with $50 \mathrm{ng}$ pGLH2B (labeled as H2B), pGLH2B(65) [labeled as H2B(65)], pGLH2B (65M) [labeled as H2B $(65 \mathrm{M})$ ], or pGLH3 (labeled as H3) reporter construct. $50 \mathrm{ng}$ pCMV-lacZ was also cotransfected in each transfection. Twenty-two hours after transfection, cells were lysed and the fold of induction was measured as described in Fig. 6A. cyclin E-Cdk2, cyclin D1-Cdk4 does not stimulate H4 transcription activation by NPAT (Fig. 9A). The results are consistent with our previous observation that NPAT is phosphorylated by cyclin $\mathrm{E} / \mathrm{Cdk} 2$, not cyclin D1/ Cdk4, in vivo (Zhao et al. 1998). From these experiments, we conclude that the effect of NPAT on histone transcription is likely to be regulated specifically by the cyclin E-Cdk2 complex.

To rule out the possibility that the effect of cyclin E-Cdk2 on NPAT-mediated transcriptional activation is simply due to the cell cycle effect of this kinase complex, we examined the effect of cyclin E-Cdk2 on NPAT-mediated transcriptional activation from the $\mathrm{H} 4$ promoter in cells $1.5 \mathrm{hr}$ after they were released from $M$ phase when the cells have not reached $S$ phase (data not shown). As shown in Figure 9C, cyclin E-Cdk2 still stimulates the NPAT-mediated $\mathrm{H} 4$ transcriptional activation when the cell cycle effect is excluded in this experiment. The results suggest that the stimulation of NPAT-mediated transcriptional activation by cyclin E-Cdk2 may result from a direct effect of the kinase complex on NPAT, such as the phosphorylation of NPAT by cyclin E-Cdk2, rather than the indirect cell cycle effect of this kinase complex.

Previous studies have suggested that the H4 SSCS mediates the cell cycle regulation of histone $\mathrm{H} 4$ gene transcription (Dailey et al. 1988; Heintz 1991). However, this hypothesis has not been proven experimentally. Here we show that both the activation of the H4 promoter by NPAT and the stimulation of NPAT-mediated transcriptional activation by cyclin E-Cdk2 are dependent on the H4 SSCS. We also observed that H4 transcription was inhibited by cotransfection of $\mathrm{p} 27$ or a dominant-negative Cdk2, known inhibitors of the $\mathrm{G}_{1}$ to-S phase transition (van den Heuvel and Harlow 1993; Polyak et al. 1994; Toyoshima and Hunter 1994), and that this inhibition is H4 SSCS dependent (data not shown). These experimental results support the idea that the H4 SSCS is critical for the cell cycle-regulated transcription of histone $\mathrm{H} 4$ genes.

\section{Both NPAT and cyclin E-Cdk2 are physically associated with the histone gene loci}

To gain further support for the idea that cyclin E-Cdk2 as well as NPAT is involved in the regulation of histone gene expression directly, we employed chromatin immunoprecipitation assays (CHIP; Braunstein et al. 1993; Crane-Robinson and Wolffe, 1998; Luo et al. 1998) to detect the association of endogenous NPAT and cyclin E proteins with histone genes in vivo. These experiments (Fig. 9D) show that the immunoprecipitates of antiNPAT antibodies are enriched for several histone DNA sequences, demonstrating directly that the endogenous NPAT is associated with the histone gene clusters. As with anti-NPAT antibodies, anti-cyclin E-specific antibodies also immunoprecipitate histone DNA sequences. In contrast, anti-cyclin D1 antibodies gave the same background signal as an anti-SV40-T control antibody 
A

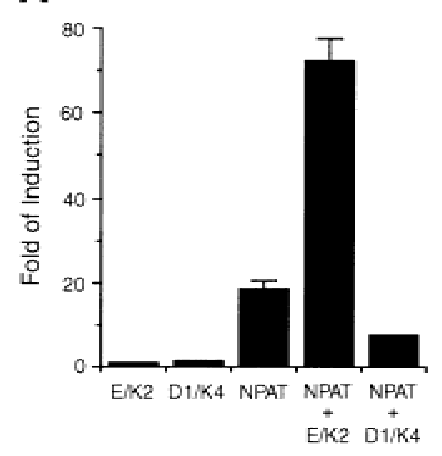

B

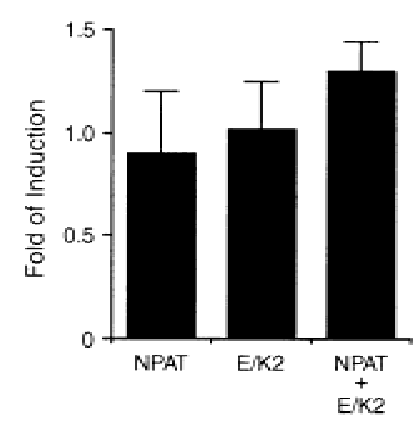

C

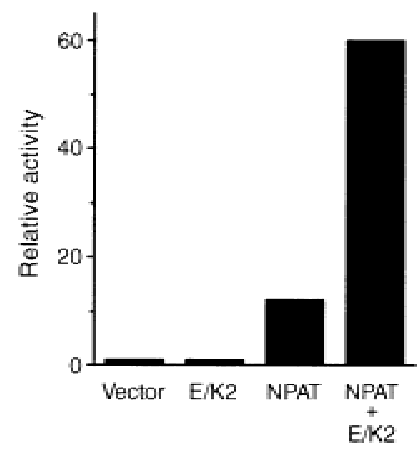

D

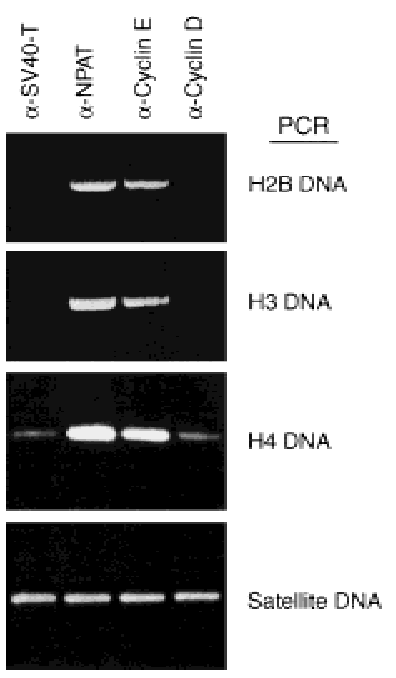

Figure 9. Cyclin E-Cdk2 regulates NPAT-mediated activation of histone gene transcription. (A) Cyclin E-Cdk2 stimulates NPATmediated transcriptional activation. U2OS cells were transfected with 50 ng pGLH4(65) together with 50 ng pCMV-lacZ, and the indicated expression plasmids. $0.5 \mu \mathrm{g}$ of each expression plasmid was used, and if needed, pCMV vector was added to bring the total amount of plasmid DNA to $1.6 \mu \mathrm{g}$. The samples were analyzed as described in Fig. 6A. (B) The stimulation of NPAT-mediated transcriptional activation by cyclin E-Cdk2 is the SSCS dependent. The experiments were carried out as described in $A$ except that the reporter used was pGLH4 (M1). (C) Cyclin E-Cdk2 stimulates NPAT-mediated H4 transcriptional activation in non-S phase cells. U2Os cells, grown on $10-\mathrm{cm}$ plates, were transfected with $300 \mathrm{ng}$ pGLH4(65) and $300 \mathrm{ng}$ pCMV-lacZ, together with indicated expression plasmids (NPAT, $6 \mu \mathrm{g}$; cyclin $\mathrm{E}$ and Cdk2, $1.5 \mu \mathrm{g}$ ). pCMV (vector) was added to bring the total plasmid DNA concentration to $9 \mu \mathrm{g} /$ plate. Five hours after transfection, Nocadazole (final concentration $70 \mathrm{ng} / \mathrm{mL}$ ) was added into the culture medium to arrest the cells in $\mathrm{M}$ phase. Cells in $\mathrm{M}$ phase were harvested by mitotic shake-off $18 \mathrm{~h}$ later. The cells were washed twice with culture medium and replated. One and one-half hours after replating, the effect of NPAT on H4 transcription was analyzed as described in Fig. 6A. The mean results from two independent experiments are shown. (D) Association of NPAT and cyclin E with histone gene clusters. Lysates prepared from U2OS cells were precipitated with the indicated antibodies. The indicated DNA sequences were detected by PCR using specific primers as described in Materials and Methods.

(Fig. 9D). As a nonspecific background control, the immunoprecipitates obtained with these four different antibodies were also subjected to PCR for a satellite DNA sequence on the $\mathrm{X}$ chromosome (Fig. 9D). No differences in the intensities of the products were observed, indicating that the enrichment for histone DNA sequence by anti-NPAT and anticyclin E antibodies is specific. The relatively strong intensities of the satellite DNA sequence bands reflect the high copy number of these sequences within the genome. We also performed PCR reactions using primers specific for other $S$ phase-regulated promoters (such as cyclin E and b-myb promoters), and we did not detect any enrichment for these DNA sequences by anti-NPAT antibodies compared with control antibodies (data not shown). The CHIP assay shows that the endogenous cyclin E protein, like the endogenous NPAT protein, is associated with histone gene loci in vivo. Interestingly, it was recently observed that cyclin $\mathrm{E}$ and $\mathrm{Cdk} 2$ are localized in the coiled bodies during the $\mathrm{G}_{1}$-to-S phase transition (Liu et al. 2000). Taken together, we conclude that cyclin E-Cdk2, as well as NPAT, is directly involved in histone gene expression.

\section{Discussion}

Regulation of CDKs and their roles in cell cycle progres- sion have been studied in great detail, yet relatively little is known about the connections between these CDKs and specific cell cycle events. Here we report that NPAT, a substrate of cyclin E-Cdk2, is associated with histone gene clusters in S phase and activates histone gene transcription. Moreover, we show that cyclin E is also associated with histone gene clusters and that cyclin E-Cdk2 enhances the NPAT-mediated activation of histone gene transcription. Thus, NPAT appears to link the cyclin E-Cdk2 kinase to the regulation of an S phase-specific event. Recently, Ma et al. (2000) observed that the phosphorylation of NAPT exhibits cell cycle-dependent changes in vivo. They have mapped the cyclin E-Cdk2 phosphorylation sites on NPAT and found that the activity of NPAT on histone gene transcription is decreased when these sites are mutated, further indicating a direct role for cyclin E-Cdk2 in regulating NPAT function (Ma et al. 2000). We propose that coordinated transcriptional activation of histone genes at the $G_{1} / S$ phase boundary may be the direct result of the activation of cyclin E-Cdk2 at this point of the cell cycle.

\section{The function of NPAT}

Transcription of histone genes has long been recognized as a cell cycle-dependent event (Schumperli 1986; 
Heintz 1991; Osley 1991; Stein et al. 1992). Despite great efforts, it is still not clear how the transcriptional activation of histone genes is regulated by the cell cycle machinery and how the transcription of five histone subtypes is coordinated during $S$ phase. We have shown that NPAT activates the transcription from the promoters of several histone genes. More important, we demonstrated that activation of histone $\mathrm{H} 2 \mathrm{~B}$ and $\mathrm{H} 4$ transcription by NPAT is mediated through the SSCSs, the promoter sequences long thought to mediate the cell cycle-dependent transcription of histone genes. These observations raise the possibility that NPAT may be a general regulatory factor of histone gene transcription during the $G_{1}$ to-S phase transition. Identification of the role of NPAT in histone gene transcription may also explain the earlier observation that inactivation of NPAT in mice causes embryonic arrest at the eight-cell stage (Di Fruscio et al. 1997). Zygotic histone gene transcription starts at the four-cell stage (Graves et al. 1985; Clarke et al. 1992; Wiekowski et al. 1997); without NPAT, the normal regulation of histone gene transcription may become impaired, thereby resulting in the embryonic arrest.

An important question that needs to be addressed in future studies is how NPAT regulates histone gene transcription. Although NPAT is found at the histone gene loci during the time when these genes are actively expressed and is physically bound to some structure in this region, we have not been able to detect direct binding of NPAT to an H4-promoter DNA sequence. These tests have been done primarily by gel shift experiments using anti-NPAT antibodies for super shifts (data not shown). We imagine that NPAT may act as a transcriptional regulator of histone gene transcription through interaction with a gene-specific factor (such as the factor that binds an SSCS). The intensity of NPAT staining is about the same as that of coilin in coiled bodies, which have an average diameter of $0.5 \mu \mathrm{m}$ (Matera 1999). If the staining intensity reflects the size of the structure a protein occupies, the accumulation of NPAT in S phase at histone gene loci would plausibly allow the protein to interact with many or all the promoters in the histone gene clusters. NPAT may thus function as a scaffold that recruits and/or organizes the multiprotein complex involved in histone gene transcription, or NPAT may cause a change in chromatin structure in the domains occupied by the histone gene clusters.

The mRNAs encoded by replication-dependent histone genes do not have poly A at their 3' ends. Instead, they have a stem-loop structure that is involved in histone mRNA 3' processing (Marzluff 1992; Melin et al. 1992; Dominski et al. 1999). Proper $3^{\prime}$ processing also plays a major role in the accumulation of histone mRNA in S phase. It is not known whether NPAT also has any effects on 3' processing, although our preliminary in vitro studies were negative (data not shown). Further experiments are needed to address this issue.

Previously, we reported that expression of NPAT promotes $S$ phase entry. Here, we show that NPAT activates histone gene transcription. Both observations point to a role for NPAT in the $\mathrm{G}_{1}$-to-S phase transition. It is not clear whether activation of histone gene transcription by NPAT is solely responsible for its ability to promote $S$ phase entry. It is possible that NPAT may activate the expression of other gene targets whose functions are also involved in S phase entry. Activation of histone gene transcription may be one of the mechanisms by which NPAT promotes $S$ phase entry.

\section{Localization of NPAT}

One of the most intriguing features of NPAT is its localization pattern in primary cells. The NPAT foci are associated with the histone cluster on chromosome 6 in both $S$ phase when cells have four such spots, as well as in non-S phase cells when there are only two NPAT foci. The association of NPAT spots with the histone gene cluster on chromosome 1 is only observed in S phase. It is not clear why the histone cluster on chromosome 6 appears to be constitutively associated with NPAT spots while the chromosome 1 cluster is associated with NPAT spots only in S phase. One possibility is that the NPAT protein is always associated with histone gene clusters, but the NPAT protein concentration at these loci is low at $G_{1}$ and $G_{2}$ phases, and the association increases dramatically when cells enter $S$ phase. As a result, the association of NPAT with chromosome 1 cluster, which is much smaller than that on chromosome 6, is not detectable during $G_{1}$ and $G_{2}$ phases and only becomes detectable in $S$ phase. Alternatively, the accumulation of NPAT at the chromosome 1 cluster might be de novo and cell cycle regulated. In either case, the accumulation of NPAT protein at the histone gene clusters on chromosome 1 is cell cycle regulated. Further studies will be needed to determine precisely how the localization of NPAT is regulated. In transformed cells, it appears that the NPAT spots are associated with both chromosome 1 and chromosome 6 clusters in all stages of interphase (data not shown), suggesting that the regulated accumulation of NPAT at histone gene clusters is altered in these cells.

\section{Coordinating the events of chromosome duplication}

It has been shown previously that cyclin E-Cdk2 regulates two $S$ phase events: DNA replication and centrosome duplication (Fang and Newport 1991; Jackson et al. 1995; Hinchcliffe et al. 1999; Lacey et al. 1999). Here, we show that another major event of $\mathrm{S}$ phase, histone gene expression, may also be regulated by cyclin E-Cdk2. Furthermore, we have identified NPAT as a downstream target that links cyclin E-Cdk2 to the regulation of histone gene transcription. DNA replication and histone synthesis are tightly coupled in S phase. Our results suggest that cyclin E-Cdk2 may provide a mechanism that coordinates initiation of both DNA replication and histone gene expression on entry into $S$ phase. Thus, cyclindependent kinases promote cell cycle transitions by coordinating the numerous cellular events within the same phase of the cell cycle. 


\section{Materials and methods}

\section{Antibodies and plasmids}

DH3 and DH4 are mouse anti-NPAT monoclonal antibodies. DH3 was described previously (Zhao et al. 1998), and DH4 was produced using a his-tagged polypeptide that contains amino acids $1082-1427$ of NPAT as the immunogen. The rabbit antiNPAT antibodies R48 and R49 were generated in two separate rabbits as described in Zhao et al. (1998), and affinity purified with a GST fusion protein containing the same region of NAPT used to generate the anti-NPAT sera. The anti- cyclin D, cyclin E, p21, and SV40 antibodies have been described previously (Zhao et al. 1998). Mouse anticoilin monoclonal antibody 5P10 (Almedia et al. 1998) was a gift from M. Carmo-Fonseca (University of Lisbon, Portugal). Rabbit anti-PML antibody was proved by K. Chang (University of Texas M.D. Anderson Cancer Center). Mouse anti-BrdU monoclonal antibody was purchased from Amersham. The fluorescein (green), Texas Red (red), or AMCA (blue) conjugated anti-mouse IgG and anti-rabbit IgG secondary antibodies were purchased from Vector Laboratories.

The expression plasmids for NPAT, cyclin E, Cdk2, cyclin D1, and Cdk4 were previously described (Zhao et al. 1998). The luciferase reporter constructs used for the transcription assays were generated by cloning the promoter fragments into the pGL3 basic luciferase reporter plasmid (Promega). The promoter fragments were made by either PCR or annealing of two synthetic oligonucleotides that correspond to appropriate promoter sequences. All promoter constructs were verified by DNA sequencing. The promoter in pGLH4-1 contains 230 nucleotides of the upstream sequence from the initiation ATG of the histone H4 (FO108; Sierra et al. 1983). The promoter sequence in pGLH4 includes nucleotides -113 to +8 of the pHu4A (H4/e) promoter (Hanly et al. 1985; Dailey et al. 1987; Albig and Doenecke 1997); pGLH4(80), pGLH4(65), and pGLH4(40) carry the nucleotide sequence from -80 to $+8,-65$ to +8 , and +40 to +8 of the H4/e promoter, respectively. pGL H4(D1) has the nucleotides between -65 and -40 deleted from the promoter of pGLH4. pGLH4(M1) is identical to pGLH4, except that there are three nucleotide substitutions in the SSCS (from TTCTCAGTTCGGTCCG to TTCTCAGTTCACTACG). This promoter has the same mutation as the previously described mutant 1.5 promoter (Dailey et al. 1988). The promoter sequence in pGLH2B includes nucleotides -120 to +1 of the H2B/r promoter (Sive et al. 1986; Albig and Doenecke 1997). pGLH2B(65) carries nucleotides -65 to +1 of the $\mathrm{H} 2 \mathrm{~B} / \mathrm{r}$ promoter. pGLH65(M) is identical to pGLH2B $(65)$, except that it carries two nucleotide substitutions in the H2B SSCS as previously described for the oct ${ }^{-} \mathrm{H} 2 \mathrm{~B}$ promoter (LaBella et al. 1988). pGLH3 contains the sequence of 300 nucleotides upstream from the initiation ATG of histone H3/a (Albig et al. 1997). The pGL3-control plasmid that carries the SV40 promoter and luciferase gene reporter was from Promega. The b-myb and dhfr reporter constructs were described previously (Hurford et al. 1997; Dick et al. 2000).

\section{Immunofluorescence staining and microscopy}

Cells were grown on glass coverslips in DMEM plus $10 \%$ fetal bovine serum. The cells were washed twice with PBS and then fixed with $4 \%$ paraformaldehyde at room temperature for 10 min. The cells were washed with PBS once again and permeabilized with $0.5 \%$ Triton X-100 in PBST (PBS plus $0.2 \%$ Tween 20 ) at room temperature for $10 \mathrm{~min}$. The permeabilized cells were incubated in a blocking solution $(5 \%$ horse serum, $5 \%$ goat serum, and $0.1 \%$ fish gelatin in PBST) at $37^{\circ} \mathrm{C}$ for $15 \mathrm{~min}$, and then incubated with primary antibodies in the blocking solu- tion at $37^{\circ} \mathrm{C}$ for $1 \mathrm{~h}$. The cells were washed with PBST at room temperature $3 \times 5$ min each, incubated with appropriate secondary antibodies in blocking solution at $37^{\circ} \mathrm{C}$ for $1 \mathrm{~h}$, and washed with PBS twice at room temperature before incubating with 4',6'-diamidino-2-phenylindole (DAPI) solution $(25 \mu \mathrm{g} / \mathrm{mL}$ DAPI in PBST) for 5 min to stain the nuclear DNA. The coverslips were mounted on glass slides with vectashield (Vector Laboratories) and sealed with nail polish. Imaging was performed using CCD and deconvolution microscopy (Scanalytics).

\section{Fluorescence in situ hybridization (FISH) analysis}

A PAC clone $(\sim 60 \mathrm{~kb})$ that carries human histone genes from the histone cluster on chromosome 1 and a BAC clone $(\sim 120 \mathrm{~kb})$ that contains histone genes from the chromosome 6 cluster were used as the templates for making the histone cluster-specific probes. The probes were labeled with digoxigenin (DIG; Roche Molecular Biochemicals) using the BioPrime kit (GIBCO $\mathrm{BRL}$ ). For three-color staining, the probe for the chromosome 6 cluster was labeled with biotin. The labeled probes were purified by S-200HR spin-column chromatography (Pharmacia), precipitated with ethanol, and dissolved in a hybridization solution containing $50 \%$ formamide, $10 \%$ dextran sulfate, and $2 \times$ SSC $(0.3 \mathrm{M} \mathrm{NaCl}, 0.03 \mathrm{M}$ sodium citrate at $\mathrm{pH} 7.0)$.

WI38 cells were grown on chamber slides, fixed, permeabilized, and stained with NPAT antibodies as described for immunofluorescence staining. The cells were fixed again with $10 \%$ paraformaldehyde at room temperature for $10 \mathrm{~min}$. The cells were washed with PBS twice and processed for FISH immediately or kept in PBS at $4^{\circ} \mathrm{C}$ for later use. The cells on the slides were dehydrated sequentially in ice-cold $70 \%, 85 \%$, and $95 \%$ ethanol, and air-dried. To denature the DNA, the cells were treated with $70 \%$ formamide in $2 \times \mathrm{SSC}$ at $80^{\circ} \mathrm{C}$ for $7 \mathrm{~min}$. The samples were dehydrated again in the ice-cold ethanol series and left to air-dry.

Labeled DNA probes were diluted to a concentration of 100 $\mathrm{ng} / \mu \mathrm{L}$ in the hybridization solution, denatured at $75^{\circ} \mathrm{C}$ for 5 $\mathrm{min}$, and then allowed to reanneal at $37^{\circ} \mathrm{C}$ for $45 \mathrm{~min}$. Five microliters of probe was placed directly on to the denatured samples and covered with a glass coverslip that was sealed with rubber cement. The hybridization was carried out at $37^{\circ} \mathrm{C}$ in a humidified chamber for 14-18 h. The samples were washed with $0.5 \times$ SSC at $72^{\circ} \mathrm{C}$ for $5 \mathrm{~min}$ and then with PN buffer $(0.1 \mathrm{M}$ sodium phosphate at $\mathrm{pH} 8.0,0.1 \%$ Nonidet $\mathrm{P}-40$ ) at room temperature three times, $2 \mathrm{~min}$ each. DIG-labeled probes were detected with $1 \times$ FITC-sheep anti-DIG (Zymed). The samples were washed again with PN buffer, followed by a counterstain with DAPI in antifade (Vector Laboratories). For three-color staining, the biotin-labeled probes were detected with $2 \times$ streptavidinTexas Red (Zymed), and the samples were mounted in vetashield without DAPI. Images were captured and processed as described for IF.

\section{Luciferase reporter assays}

Cells (U2OS or SAOS2 as indicated) were grown on six-well plates and transfected with a luciferase reporter construct and appropriate expression plasmids. The cells were also cotransfected with a $\beta$-galactosidase expression plasmid (50 ng pCMVlacZ/well) to normalize the transfection efficiency. Transfections were carried out using FuGENE 6 (Roche Molecular Biochemicals). At the indicated times after transfection, the cells were lysed with the Promega Reporter Lysis Buffer at room temperature for 15-20 min. The luciferase and $\beta$-galactosidase activities of the lysates were measured as suggested by Promega. 


\section{BrdU incorporation analysis}

To measure the percentage of transfected cells that are in $S$ phase, cells were grown on glass coverslips and transfected as described in Figure 6A. To monitor the transfected cells, $100 \mathrm{ng}$ of pEGFP (Clontech) was cotransfected. To label the cells in S phase, $50 \mu \mathrm{M}$ BrdU was added into the culture medium $30 \mathrm{~min}$ before the cells were fixed for analysis. The BrdU-positive cells were detected by immunofluorescence staining as described above. More than 100 GFP positive cells in each experiment were examined, and the percentages of BrdU-positive cells were calculated.

\section{Chromatin immunoprecipitation assays}

The CHIP assays were carried out with endogenous histone promoters in U2OS cells. The assays were performed essentially as previously described (Braunstein et al. 1993; Luo et al. 1998), except that the dilution buffer was changed to $50 \mathrm{mM}$ Tris- $\mathrm{HCl}$ (pH 8.0); $200 \mathrm{mM} \mathrm{NaCl}$; 0.5\% Triton X-100; 1 mM EDTA; 0.5 mM PMSF; $0.5 \mathrm{mM}$ Benzamine-HCl; $5 \mu \mathrm{g} / \mathrm{mL}$ peptin A, aprotinin, and leupeptin. The chromatin was sonicated to $\sim 0.5-1 \mathrm{~kb}$. The reversion of cross-linking was done by incubating the samples at $65^{\circ} \mathrm{C}$ for $6-12 \mathrm{~h}$. Monoclonal antibodies Pab419 ( $\alpha$ SV40-T), DH3 ( $\alpha$-NPAT), HE67 and HE111 ( $\alpha$-cyclin E), and HD1 and HD11 ( $\alpha$-cyclin D1) were used for the immunoprecipitation. For amplification of $\mathrm{H} 4$ sequence, two primers $\left(5^{\prime}\right.$ : GCGGGACTTCCCGCCGACTTCTTC; 3': GCAGTACTTTACGGTGG-CGCTTAGC) were used to generate a 190-bp product that covers about a $120-\mathrm{bp}$ promoter region and 70-bp 5' coding region of histone $\mathrm{H} 4 / \mathrm{e}$ gene. For $\mathrm{H} 2 \mathrm{~B}$, the primers (5': GGATTTGCGAATCCTGATTGGGCA; 3': AGCACTGTGTAGCTATAAAGCGCC) were used to amplify a 180-bp promoter sequence upstream from the initiation ATG of $\mathrm{H} 2 \mathrm{~B} / \mathrm{r}$. For H3, the primers (5': CTGTAGAGTTGGAATAGAATATAG; 3': ACCCAACACTAGCGCAAATACGCC) were used to amplify a 175 -bp sequence (20 nucleotides upstream from the initiation ATG) in the H3/a promoter region. As a control, a pair of primers (5': GATCCGCAAGGGATATTTGGACC; 3': GTAGAAAAAGTGTGTCAAACTGC) were used to amplify a 170-bp satellite DNA sequence (Waye and Willard 1985).

\section{Acknowledgments}

We thank M. Classon, N. Dyson, and J. Settleman for suggestions and critical reading of this manuscript. We thank W. Harper for communicating results before publication. We also thank B. Graveley for help with in vitro processing experiments, $\mathrm{H}$. Chou for providing p27 expression plasmid, M. Carmo-Fonseca and $\mathrm{E}$. Chan for proving antibodies to human coilin, and $\mathrm{K}$. Chang for providing PML antibody. Deconvolution microscopy was performed at the Whitehead Institute Microscopy Facility. This work is supported by an American Cancer Society Fellowship to J.Z., a Leukemia Society of America Fellowship to B.K.K., a Karen Grunebaum Cancer Research Fellowship and a Howard Hughes Medical Student Fellowship to D.A.B., and grants from NIH to E.H.

The publication costs of this article were defrayed in part by payment of page charges. This article must therefore be hereby marked "advertisement" in accordance with 18 USC section 1734 solely to indicate this fact.

\section{References}

Albig, W. and Doenecke, D. 1997. The human histone gene clusters at the D6S105. Hum. Genet. 101: 284-294.
Allen, B.S., Stein, J.L., Stein, G.S., and Ostrer, H. 1991. Singlecopy flanking sequences in human histone gene clusters map to chromosomes 1 and 6. Genomics 10: 486-488.

Almeida, F., Saffrich, R., Ansorge, W., and Carmo-Fonseca, M. 1998. Microinjection of anti-coilin antibodies affects the structure of coiled bodies. J. Cell Biol. 142: 899-912.

Andrade, L.E., Chan, E.K., Raska, C.L., Peebles, C.L., Roos, G., and Tan, E.M. 1991. Human autoantibody to a novel protein of the nuclear coiled body: Immunological characterization and cDNA cloning of p80-coilin. J. Exp. Med. 173: 14071419.

Artishevsky, A., Wooden, S., Sharma, A., Resendez, E., Lee, A.S. 1987. Cell-cycle regulatory sequences in a hamster histone promoter and their interactions with cellular factors. Nature 328: 823-827.

Braunstein, M., Rose, A.B., Holmes, S.G., Allis, C.D., and Broach, J.R. 1993. Transcriptional silencing in yeast is associated with reduced nucleosome acetylation. Genes \& Dev. 7: 592-604.

Clarke, H., Oblin, C., and Bustin, M. 1992. Developmental regulation of chromatin composition during mouse embryogenesis: Somatic histone $\mathrm{H1}$ is first detectable at the 4-cell stage. Development 115: 791-799.

Crane-Robinson, C. and Wolffe, A. 1998. Immunological analysis of chromatin: FIS and CHIPS. Trends Genet. 14: 477-480.

Dailey, L., Roberts, S.B., and Heintz, N. 1987. RNA polymerase II transcription factors H4TF-1 and H4TF-2 require metal to bind specific DNA sequences. Mol. Cell. Biol. 7: 4582-4584.

1988. Purification of the human histone H4 gene-specific transcription factors H4TF-1 and H4TF-2. Genes \& Dev. 2: 1700-1712.

Dick, F.A., Sailhamer, E., and Dyson, N. 2000. Mutagenesis of the pRB pocket reveals that cell cycle arrest functions are separable from binding to viral oncoproteins. Mol. Cell. Biol. 20: $3715-3727$.

Di Fruscio, M.D., Weiger, H., Vanderhyden, B.C., Imai, T., Shiomi, T., Hori, T., Jaenisch, R., and Gray, D.A. 1997. Proviral inactivation of the Npat gene of Mpv 20 mice results in early embryonic arrest. Mol. Cell. Biol. 17: 4080-4086.

Dominski, Z. and Marzluff, W.F. 1999. Formation of the 3' end of histone mRNA. Gene 239: 1-14.

Dominski, Z., Zheng, L.X., Sanchez, R., and Marzluff. 1999. The stem-loop binding protein facilitates $3^{\prime}$ end formation by stabilizing U7 snRNP binding to the histone pre-mRNA. Mol. Cell. Biol. 19: 3561-3570.

Dulic, V., Lees, E., and Reed, S. 1992. Association of human cyclin $E$ with a periodic $\mathrm{G}_{1}-\mathrm{S}$ phase protein kinase. Science 257: 1958-1961.

Dyck, J.A., Maul, G.G., Miller, W.H., Chen, J.D., Kakizuka, A., and Evans, R.M. 1994. A novel Macromolecular Structure is a target of the promyelocyte-retinoic acid receptor oncoprotein. Cell 76: 333-343.

Fang, F. and Newport, J.W. 1991. Evidence that the $\mathrm{G}_{1}-\mathrm{S}$ and $\mathrm{G}_{2}-\mathrm{M}$ transitions are controlled by different cdc2 proteins in higher eukaryotes. Cell 66: 731-742.

Fletcher, C., Heintz, N., and Roeder, R.G. 1987. Purification and characterization of OTF-1, a transcription factor regulating cell cycle expression of a human histone $\mathrm{H} 2 \mathrm{~b}$ gene. Cell 51: 773-781.

Frey, M.R. and Matera, A.G. 1995. Coiled bodies contain U7 small nuclear RNA and associate with specific DNA sequences in interphase human cells. Proc. Natl. Acad. Sci. 92: 5915-5919.

Fu, X.D. and Maniatis, T. 1990. Factor required for mammalian spliceosome assembly is localized to discrete regions in the nucleus. Nature 343: 437-441. 
Graves, R.A., Marzluff, W.F., Giebelhaus, D.H., and Schultz, G.A. 1985. Quantitative and qualitative changes in histone gene expression during early mouse embryo development. Proc. Nat1. Acad. Sci. 82: 5685-5689.

Hanly, S.M., Bleecker, G.C., and Heintz, N. 1985. Identification of promoter elements necessary for transcriptional regulation of a human histone $\mathrm{H} 4$ gene in vitro. Mol. Cell. Biol. 5: $380-389$.

Harbour, J.W., Luo, R.X., Dei Santi, A., Postigo, A.A., and Dean, D.C. 1999. Cdk phosphorylation triggers sequential intramolecular interactions that progressively block $\mathrm{Rb}$ functions as cells move through $\mathrm{G}_{1}$. Cell 98: 859-869.

Heintz, N. 1991. The regulation of histone gene expression during the cell cycle. Biochim. Biophys. Acta 1088: 327-339.

Herrera, R.E., Chen, F., and Weinberg, R.A. 1996. Increased histone $\mathrm{H} 1$ phosphorylation and relaxed chromatin structure in Rb-deficient fibroblasts. Proc. Natl. Acad. Sci. 93: 1151011515.

Hinchcliffe, E.H., Li, C., Thompson, E.A., Maller, J.L., and Sluder, G. 1999. Requirement of Cdk2-cyclin E activity for repeated centrosome reproduction in Xenopus egg extracts. Science 283: 851-854.

Hinds, P.W., Mittnacht, S., Dulic, V., Arnold, A., Reed, S.I., and Weinberg, R.A. 1992. Regulation of retinoblastoma protein functions by ectopic expression of human cyclins. Cell 70: $993-1006$.

Huang, S. and Spector, D. 1992. U1 and U2 small nuclear RNAs are present in nuclear speckles. Proc. Natl. Acad. Sci. 89: 305-308.

Hurford, R.K., Cobrinik, D., Lee., M.H., and Dyson, N. 1997. $\mathrm{pRB}$ and $\mathrm{p} 107 / \mathrm{p} 130$ are required for the regulated expression of different sets of E2F responsive genes. Genes \& Dev. 11: $1447-1463$.

Jackson, P.K., Chevalier, S., Philippe, M., and Kirschner, M.W. 1995. Early events in DNA replication require cyclin E and are blocked by p21CIP. J. Cell Biol. 130: 755-769.

Jantzen, H.M., Admon, A., Bell, S.P., and Tjian, R. 1990. Nucleolar transcription factor hUBF contains a DNA-binding motif with homology to HMG proteins. Nature 344: 830-836.

Jiang, W., Jimenez, G., Wells, N.J., Hope, T.J., Wahl, G.M., and Hunter, T. 1998. PRC1: A human mitotic spindle-associated CDK substrate protein required for cytokinesis. Mol. Cell 2: $877-885$

Koff, A., Giordano, C., Desai, D., Yamashita, K., Harper, W., Elledge, S., Nishimoto, T., Morgan, D., Franza, R., and Roberts, J. 1992. Formation and activation of a cyclin E-Cdk2 complex during the $\mathrm{G}_{1}$ phase of the human cell cycle. Science 257: 1689-1694.

Kornberg, R.D. and Lorch, Y. 1999. Twenty-five years of the nucleosome: Fundamental particle of the eukaryote chromosome. Cell 98: 285-294.

LaBella, F., Sive, H.L., Roeder, R.G., and Heintz, N. 1988. Cellcycle regulation of a human histone $\mathrm{H} 2 \mathrm{~b}$ gene is mediated by the H2b subtype-specific consensus element. Genes \& Dev. 2: 32-39.

LaBella, F., Gallinari, P., Mckinney, J., and Heintz, N. 1989. Histone H1 subtype-specific consensus elements mediate cell cycle-regulated transcription in vitro. Genes \& Dev. 3: 1982-1990.

Lacey, K.R., Jackson, P., and Stearns, T. 1999. Cyclin-dependent kinase control of centrosome duplication. Proc. Natl. Acad. Sci. 96: 2817-2822.

Lam, E.W. and Watson, R.J. 1993. An E2F-binding site mediates cell-cycle regulated repression of mouse B-myb transcription. EMBO J. 12: 2705-2713.
Lamond, A.I. and Earnshaw, W.C. 1998. Structure and function in the nucleus. Science 280: 547-553.

Liu, J.-L., Hebert, M.D., Ye, Y., Templeton, D.J., Kung, H.-J., and Matera, A.G. 2000. Cell cycle-dependent localization of the CDK2-cyclin E complex in Cajal (coiled) bodies. J. Cell Sci. 113: $1543-1552$

Luo, R.X., Postigo, A.A., and Dean, D. 1998. Rb interacts with histone deacetylase to repress transcription. Cell 92: 463 473.

Martinelli, R. and Heintz, N. 1994. H1TF2A, the large subunit of a heterodimeric, glutamine-rich CCAAT-binding transcription factor involved in histone $\mathrm{H} 1$ cell cycle regulation. Mol. Cell. Biol. 14: 8322-8332.

Ma, T., Van Tine, B.A., Yue, W., Garrett, M., Nelson, D., Adams, P.D., Wang, J., Qin, J., Chow, L.T., and Harper, J.W. 2000. Cell cycle-regulated phosphorylation of p220 NPAT by cyclin E/Cdk2 in cajal bodies promotes histone gene transcription. Genes \& Dev. 14: (this issue).

Marzluff, W.F. 1992. Histone 3' ends: Essential and regulatory functions. Gene Expression. 2: 93-97.

Matera, A.G. 1999. Nuclear bodies: Multifaceted subdomains of the interchromatin space. Trends Cell Biol. 9: 302-309.

Melin, L., Soldati, D., Streit, A., and Schumperli, D. 1992. Biochemical demonstration of complex formation of histone pre-mRNA with U7 small unclear ribonucleoprotein and hairpin binding factors. EMBO I. 11: 691-697.

Ohtsubo, M. and Roberts, J.M. 1993. Cyclin-dependent regulation of $G_{1}$ in mammalian fibroblasts. Science 259: 19081912.

Ohtsubo, M., Theodoras, A.M., Schumacher, J., Roberts, J.M. and Pagano, M. 1995. Human cyclin E, a nuclear protein essential for the $\mathrm{G}_{1}$-to-S phase transition. Mol. Cell. Biol. 15: $2612-2624$.

Osley, M.A. 1991. The regulation of histone synthesis in the cell cycle. Annu. Rev. Biochem. 60: 827-861.

Oswald, F., Dobner, T., and Lipp, M. 1996. The E2F transcription factor activates a replication-dependent human H2A gene in early $\mathrm{S}$ phase of the cell cycle. Mol. Cell. Biol. 16: $1889-1895$.

Perkins, N.D., Felzien, L.K., Betts, J.C., Leung, K., Beach, D.H., and Nabel, G.J. 1997. Regulation of NF-kB by cyclin-dependent kinases associated with the p300 coactivator. Science 275: 523-527.

Polyak, K., Lee, M.H., Erdjument-Bromage, H., Koff, A., Roberts, J.M., Tempst, P., and Massague, J. 1994. Cloning of p27kip1, a cyclin-dependent kinase inhibitor and a potential mediator of extracellular antimitogenic signals. Cell 78: 5966.

Ramsey-Ewing, A., van Wijnen, A.J., Stein, G.S. and Stein, J.L. 1994. Delineation of a human histone $\mathrm{H} 4$ cell cycle element in vivo: The master switch for $\mathrm{H} 4$ gene transcription. Proc. Nat1. Acad. Sci. 91: 4475-4479.

Raska, I., Ochs, R.L., Anddrade, L.E., Chan, E.K.L., Burlingame, R., Peebles, C., Gruol, D., and Tan, E. 1990. Association between nucleolus and the coiled body. J. Struct. Biol. 104: 120-127.

Resnitzky, D., Gossen, M., Bujard, H., and Reed, S.I. 1994. Acceleration of the $G_{1} / S$ phase transition by expression of cyclins D1 and E with an inducible system. Mol. Cell. Biol. 14: $1669-1679$.

Robbins, E. and Borun, T.W. 1967. The cytoplasmic synthesis of histones in Hela cells and its temporal relationship to DNA replication Proc. Natl. Acad. Sci. 57: 409-416.

Ruffner, H., Jiang, W., Craig, A.G., Hunter, T., and Verma, I.M. 1999. BRCA1 is phosphorylated at serine 1497 in vivo at a cyclin-dependent kinase 2 phosphorylation site. Mol. Cell. 
Biol. 19: 4843-4854.

Schumperli, D. 1986. Cell-cycle regulation of histone gene expression. Cell 45: 471-472.

Seghezzi, W., Chua, K., Shanahan, F., Gozani, O., Reed, R., and Lees, E. 1998. Cyclin E associates with components of the pre-mRNA splicing machinery in mammalian cells. Mol. Cell. Biol. 18: 4526-4536.

Segil, N., Roberts, S.B., and Heintz, N. 1991. Mitotic phosphorylation of the Oct-1 homeodomain and regulation of oct-1 DNA binding activity. Science 254: 1814-1816.

Shanahan, F., Seghezzi, W., Parry, D., Mahony, D., and Lees, E. 1999. Cyclin E associates with BAF155 and BRG1, components of the mammalian SWI-SNF complex, and alters the ability of BRG1 to induce growth arrest. Mol. Cell. Biol. 19: 1460-1469.

Sheaff, R.J., Groudine, M., Gordon, M., Roberts, J.M., and Clurman, B.E. 1997. Cyclin E-Cdk2 is a regulator of p27kip1. Genes \& Dev. 11: 1464-1478.

Sierra, F., Stein, G.S., and Stein, J.L. 1983. Structure and in vitro transcription of a human $\mathrm{H} 4$ histone gene. Nucleic Acid. Res. 11: 7069-7086.

Sive, H.L., Heintz, N., and Roeder, R.G. 1986. Multiple sequence elements are required for maximal in vitro transcription of a human histone H2B gene. Mol. Cell. Biol. 6: 33293340.

Stein, G.S., Stein, J.L., van Wijnen, A.J., and Lian, J.B. 1992. Regulation of histone gene expression. Curr. Opin. Cell Biol. 4: $166-173$.

Toyoshima, H. and Hunter, T. 1994. p27, a novel inhibitor of $\mathrm{G}_{1}$ cyclin-Cdk protein kinase activity, is related to p21. Cell 78: $67-74$.

Tsai, L.-H., Lees, E., Faha, B., Harlow, E., and Riabowol, K. 1993. The cdk2 kinase is required for the $\mathrm{G}_{1}$-to-S transition in mammalian cells. Oncogene 8: 1593-1602.

van den Heuvel, S. and Harlow, E. 1993. Distinct roles for cyclin-dependent kinases in cell cycle control. Science 262: 2050-2054.

van Wijnen, A.J., van den Ent, I., Lian, J.B., Stein, J.L., and Stein, G.S. 1992. Overlapping and CpG methylation-sensitive protein-DNA interactions at the histone $\mathrm{H} 4$ transcriptional cell cycle domain: Distinction between two human H4 gene promoters. Mol. Cell. Biol. 12: 3273-3287.

van Wijnen, A.J., van Gurp, M.F., de Ridder, M.C., Tufarelli, C., Last, T.J., Birnbaum, M., Vaughan, P.S., Giordano, A., Ktek, W., Neufeld, E., et al. 1996. CDP/cut is the DNA binding subunit of histone gene transcription factor HiNF-D: A mechanism for gene regulation at the $G_{1} / S$ phase cell cycle transition point independent of transcription factor E2F. Proc. Nat1. Acad. Sci. 93: 11516-11521.

Vaughan, P.S., Aziz, F., van Wijnen, A.J., Wu, S., Harada, H., Taniguchi, T., Soprano, K.J., Stein, J.L., and Stein, G.S. 1995. Activation of a cell-cycle-regulated histone gene by the oncogenic transcription factor IRF-2. Nature 377: 362-365.

Waye, J.S. and Willard, H.F. 1985. Chromosome-specific $\alpha$ satellite DNA: Nucleotide sequence analysis of the 2.0 kilobasepair repeat from the human $\mathrm{X}$ chromosome. Nucleic Acid. Res. 13: 2731-2743.

Wells, J.M., Illenye, S., Magae, J., Wu, C.L., and Heintz, N.H. 1997. Accumulation of E2F-4.DP-1 DNA binding complexes correlates with induction of dhfr and rep3 genes during the $\mathrm{G}_{1}$ to $\mathrm{S}$ phase transition. J. Biol. Chem. 272: 4483-4492.

Wiekowski, M., Miranda, M., Nothias, J., and DePamphilis, M.L. 1997. Changes in histone synthesis and modification at the beginning of mouse development correlate with the establishment of chromatin mediated repression of transcription. J. Cell Sci. 110: 1147-1158.
Wu, F. and Lee, A.S. 1998. Identification of AP-2 as an interactive target of $\mathrm{Rb}$ and a regulator of the $\mathrm{G}_{1} / \mathrm{S}$ control element of the hamster histone H3.2 promoter. Nucleic Acid. Res. 26: 4837-4845.

Yagi, H., Kato, T., Nagata, T., Habu, T., Nozaki, M., Matsushiro, A., Nishimune, Y., and Morita, T. 1995. Regulation of the mouse histone H2A.X gene promoter by the transcription factor E2F and CCAAT binding protein. J. Biol. Chem. 270: 18759-18765.

Zhao, J., Dynlacht, B., Imai, T., Hori, T., and Harlow, E. 1998. Expression of NPAT, a novel substrate of cyclin E-Cdk2, promotes S phase entry. Genes \& Dev. 12: 456-461.

Zhu, L., Harlow, E., and Dynlacht, B.D. 1995. p107 uses a p21CIP1-related domain to bind cyclin/cdk2 and regulate interactions with E2F. Genes \& Dev. 9: 1740-1752. 


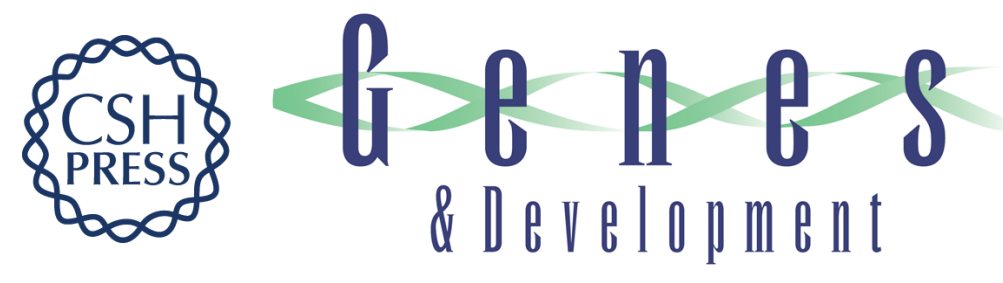

\section{NPAT links cyclin E-Cdk2 to the regulation of replication-dependent histone gene transcription}

Jiyong Zhao, Brian K. Kennedy, Brandon D. Lawrence, et al.

Genes Dev. 2000, 14:

Access the most recent version at doi:10.1101/gad.827700

References

This article cites 77 articles, 46 of which can be accessed free at:

http://genesdev.cshlp.org/content/14/18/2283.full.html\#ref-list-1

License

Email Alerting

Receive free email alerts when new articles cite this article - sign up in the box at the top Service right corner of the article or click here.

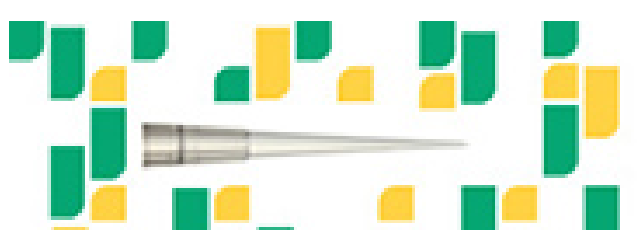

Focused on your science. 